\title{
The Phenomenon of Treatment Dropout, Reasons and Moderators in Acceptance and Commitment Therapy and Other Active Treatments: A Meta-Analytic Review
}

\author{
Maria Karekla a , Pinelopi Konstantinou ${ }^{\mathrm{a}}$, Myria Ioannou ${ }^{\mathrm{a}}$, Ioannis Kareklas ${ }^{\mathrm{b}}$, \\ Andrew T. Gloster ${ }^{\mathrm{c}}$
}

[a] University of Cyprus, Nicosia, Cyprus. [b] University at Albany, New York, NY, USA. [c] University of Basel, Basel, Switzerland.

Clinical Psychology in Europe, 2019, Vol. 1(3), Article e33058, https://doi.org/10.32872/cpe.v1i3.33058

Received: 2019-01-13 • Accepted: 2019-05-09 • Published (VoR): 2019-09-20

Handling Editor: Cornelia Weise, Philipps-University of Marburg, Marburg, Germany

Corresponding Author: Maria Karekla, Department of Psychology, University of Cyprus, P.O. Box 20537, Nicosia 1678, Cyprus. Tel: 35722 892100; Fax: 35722 892071. E-mail: mkarekla@ucy.ac.cy

\begin{abstract}
Background: Treatment dropout is one of the most crucial issues that a therapist has to face on a daily basis. The negative effects of premature termination impact the client who is usually found to demonstrate poorer treatment outcomes. This meta-analysis reviewed and systematically examined dropout effects of Acceptance and Commitment Therapy (ACT) as compared to other active treatments. The goals of this study were to compare treatment dropout rates and dropout reasons, examine the influence of demographic variables and identify possible therapy moderators associated with dropout.

Method: The current meta-analysis reviewed 76 studies of ACT reporting dropout rates for various psychological and health-related conditions.

Results: Across reviewed studies $(\mathrm{N}=76)$, the overall weighted mean dropout rate was $17.95 \%$ $(\mathrm{ACT}=17.35 \%$ vs. comparison conditions $=18.62 \%)$. Type of disorder, recruitment setting and therapists' experience level were significant moderators of dropout. The most frequently reported reasons for dropout from ACT were lost contact, personal and transportation difficulties, whereas for comparative treatments they were lost contact, therapy factors and time demands.

Conclusion: Given that most moderators of influence are not amenable to direct changes by clinicians, mediation variables should also be explored. Overall, results suggest that ACT appears to present some benefits in dropout rates for specific disorders, settings and therapists.
\end{abstract}

\section{Keywords}

acceptance and commitment therapy, dropout, attrition, meta-analysis, premature termination 


\section{Highlights}

- There was no difference in dropout rate between ACT and control conditions

(17.35\% vs.18.62\%). Significant moderators were client disorder, therapists' experience level and recruitment and setting.

- Comparison condition frequently reported therapy related dropout factors, suggesting that ACT may be a more acceptable option.

Acceptance and Commitment Therapy (ACT), is a so-called third wave Cognitive Behavior Therapy (CBT) and has been applied successfully to treat numerous problems and disorders (Hayes, Luoma, Bond, Masuda, \& Lillis, 2006; Ruiz, 2012). ACT helps clients choose to do what takes them closer to their goals (especially when dealing with problematic thoughts and emotions) rather than aiming to reduce symptoms directly (Hayes, Hayes, Strosahl, \& Wilson, 2012). The focus is placed on the experience of the person and the function of any behavior rather than on actions being carried out based on the literal content of a belief (Hayes et al., 2006). The overall aim of treatment is to increase psychological flexibility or the ability to fully contact the present moment, choosing to act guided by the person's values in the context at hand (Fletcher \& Hayes, 2005). Most existing reviews and meta-analyses of ACT support that it is at least as equally effective as traditional Cognitive Behavioral Therapy (tCBT) on indices of symptom reduction and more effective than other comparison conditions (A-Tjak et al., 2015; Powers, Vörding, \& Emmelkamp, 2009; Ruiz, 2012).

Treatment outcomes and effectiveness, however, are affected not only by the specific treatment provided but also by other factors such as premature termination/dropout or non-completion of the specified interventions (Barrett, Chua, Crits-Christoph, Gibbons, \& Thompson, 2008). Premature therapy termination or treatment dropout is a significant problem or obstacle limiting the effectiveness of any therapeutic approach and results in detrimental outcomes in patients (Barrett et al., 2008; Wierzbicki \& Pekarik, 1993). Unfortunately, there is no consensus definition about what constitutes treatment dropout. General definitions of dropout include: termination of the intervention prior to the patient recovering from the problem(s) for which treatment was initially sought (Hatchett \& Park, 2003; Swift, Callahan, \& Levine, 2009), or treatment termination without the agreement of the therapist and before the scheduled end point (Stone \& Rutan, 1984). However, in research protocols premature termination may be considered as missing a number of pre-arranged sessions (e.g., four consecutive weeks in DBT; Linehan, 1993) irrespective of the patient's recovery status.

Reviews and meta-analyses of this phenomenon focus on examining first the rates of dropout and, secondly, variables associated with its occurrence. Swift and Greenberg (2012) examined dropout definition as a moderator of dropout rates and found higher rates when the therapist judged dropout status, compared to other definitions. This was 
one of the first comprehensive reviews of the dropout phenomenon encompassing various forms of psychotherapy and concluded that 1 in 5 clients drop out prematurely, a rate somewhat lower than previous reviews (e.g., Wierzbicki \& Pekarik, 1993). Client diagnosis, age, education, gender, marital status, time-limitations of treatment, use of manual or protocol, treatment setting, providers' level of experience, dropout definition, study type and search strategy were found to be significant moderators of dropout. However, this meta-analysis did not include studies of third wave psychological treatments, like ACT. Moreover, it focused only on adult populations and did not include substance or alcohol abuse disorders, health-related problems (e.g., weight management, emotional burnout), and self-help interventions. Finally, it focused on providing a broad analysis of premature discontinuation in psychological treatments and not on reasons for dropout.

This study aims to examine the dropout phenomenon in ACT (compared to other active interventions) because of ACT's emphasis on connecting clients with their deeply held values and through this process to motivate them towards behavior change. If ACT is successful in mobilizing individuals via the treatment process, we expect that this would prevent premature termination and thus ACT would result in lower dropout rates compared to other interventions. To date, only one meta-analysis on dropout has included ACT (Ong, Lee, \& Twohig, 2018). This study found that only therapist experience significantly predicted dropout, specifically that when ACT was provided by master's level therapists higher dropout rates were observed, compared to other levels of therapists' experience (e.g., PhD level psychologist, MD physician, graduate student). However, understanding dropout in ACT can be further facilitated in four important ways. First, inclusion of variables found to predict dropout in previous meta-analyses (e.g., gender, race, marital status, employment and years of education) will allow for comparison across studies and methods (e.g., Swift \& Greenberg, 2012). Second, inclusion of variables that assess how the therapy and study were implemented (e.g., length of intervention, hours of intervention, setting, definition of dropout, study type, year of publication and region) can reveal clues as to how interventions can actively minimize dropout. Third, testing the reasons and timing of dropouts provides hypotheses for researchers and therapists to actively intervene to prevent this phenomenon of paramount clinical significance. Finally, some methodological details regarding comparison groups are worthy of reexamination. For example, we believe that including waitlist control conditions in the comparisons may bias the dropout findings in favor of waitlist control. This is because people on the waitlist are fundamentally different to patients in a control condition. In the waitlist, patients usually maintain hope that things will get better once the treatment begins and are not motivated to actively change during the waiting period. When clients do drop out during this period, by definition it has nothing to do with the active treatment. Thus a cleaner comparison of treatment dropout should be carried out between different active treatments (including active controls). Towards this goal, comparative conditions should be other active interventions. 
A minority of patients may drop out because they improved or met their goals; however numerous individuals drop out because of a problem with the treatment or therapists or for other unforeseen circumstances. Specifically, proposed problems or reasons associated with increased dropout rates include: client demographic characteristics (e.g., younger age, female gender, low socioeconomic status; Wierzbicki \& Pekarik, 1993); type of psychopathological difficulties (e.g., eating or personality disorders); therapist characteristics (e.g., provider in training); therapy setting (e.g., university-based clinics); and specific factors (e.g., non-time limited therapy), and environmental variables or acute problems that take greater priority (Bados, Balaguer, \& Saldaña, 2007; Roe, Dekel, Harel, \& Fennig, 2006; Swift \& Greenberg, 2012).

Researching these reasons is difficult as variables and methods vary widely depending on the study and its focus, the population studied, the treatment setting or the treatment offered (Roe et al., 2006; Todd, Deane, \& Bragdon, 2003). However, there is an agreement that certain common reasons account for dropout. These include: lack of improvement or accomplishment of goals, dissatisfaction with the treatment, and environmental obstacles and constraints (Hunsley, Aubry, Verstervelt, \& Vito, 1999; Pekarik, 1992; Roe et al., 2006; Todd et al., 2003). In addition to common factors, clients report specific reasons for discontinuation, including: external circumstantial problems and difficulties (e.g., transportation problems, moving away, timetables), illness and new responsibilities, improvement due to therapy, satisfactory achievement of treatment goals, high treatment costs, dissatisfaction with the therapist and psychotherapy, no need for services and need for independence and trying to solve problems without therapy (Bados et al., 2007; Roe et al., 2006; Todd et al., 2003).

Interestingly, very little attention has been given to the timing during treatment when premature termination occurs and most studies do not even report this information. Some have proposed that the first two sessions are critical for premature termination, given that most dropouts $(70 \%)$ occur at this point, making it a critical period to successfully engage the client in treatment (Olfson, Mojtabai, Sampson, Hwang, \& Kessler, 2009). Karekla (2004) observed that in a comparison trial of CBT vs. ACT for panic disorder, though dropout rates between the two approaches were similar, most individuals who dropped out in the CBT condition did so immediately after the introduction of exposure. Such a pattern was not evident for the ACT group, where individuals dropped out at various times during treatment unrelated to specific treatment components. It was concluded that ACT might present an advantage over CBT not in terms of symptom reduction but that it may better prepare individuals to engage in exposure of previously avoided internal and external events and in dealing with the dropout problem. To date, none of the reported reviews or meta-analyses of ACT have examined in depth dropout, dropout reasons, extensive list of moderators, and compared to active treatments. 


\section{Current Study}

The purpose of this study is to examine dropout rates, dropout reasons' associated factors, and potential moderators of dropout, in ACT compared to active comparison conditions. The goals of this study were to: (i) compare treatment dropout rate and timing between ACT and other active treatments; (ii) examine the influence of demographic variables such as age, gender, treatment setting, race, education, duration of treatment, ethnicity and diagnosis on dropout; (iii) identify possible therapy-associated moderators of dropout; and (iv) examine timing and possible reasons for dropout.

\section{Method}

This review was registered in the International Prospective Register of Systematic Reviews (see Supplementary Materials).

\section{Literature Search}

The literature search was conducted using the computerized literature databases Google Scholar, EBSCOhost (Academic Search Ultimate, Medline, Psychology and Behavioral Sciences Collection, PsycARTICLES, PsychInfo, OpenDissertations) and Science Direct (until June 2018) with the following keywords based on title: "Acceptance and Commitment Training”, "Acceptance-based behavior therapy", "ACT-based", "Experiential avoidance", "Psychological flexibility”, "RFT-based”, "CBS-based”, "Third wave CBT therapies" "Acceptance and Commitment Therapy", and "ACT"; alone first and then also combined with the terms "drop out" or "dropout" or "discontinuation" or "outcome" or "premature termination" or "termination". The reference lists of all identified articles were examined for additional potentially eligible studies, as well as existing meta-analyses and reviews. A request for unpublished studies was sent to the Acceptance and Commitment Therapy (ACT) listserv (https://contextualscience.org/emailing_lists), as well as to the primary or secondary authors of identified articles, via email.

\section{Eligibility Criteria}

Identification and selection of the included studies was performed by the second author, a clinical psychology doctoral student, who was first trained and instructed in the procedure of conducting meta-analysis by the first and last authors. Everything was checked by the first author. The last three authors all have experience in meta-analysis and served to check all steps taken in the process of this study.

This study includes all published and unpublished (e.g., dissertation) Acceptance and Commitment Therapy studies that included dropout information and met the following criteria. Studies were included if they: (1) were in English, (2) reported dropout rates after beginning psychotherapy or reported no dropouts (i.e., all participants completed treat- 
ment), and (3) used an active comparison condition. Studies were excluded if: (a) data originated from the same sample as another included study (so as to avoid violating the meta-analytic assumption of data independence); (b) information to calculate effect sizes was lacking and contact with authors was not possible; and (c) case studies.

The literature search resulted in 4399 articles in total. After screening the titles and abstracts, and following the examination of the full papers, 76 studies met all aforementioned inclusion criteria and were retained for analysis (see Figure 1 for procedure details). Based on the Rosenthal's suggestions for computing the fail-safe n, it was found that the total $\mathrm{Z}$ value was -1.181 and the number of missing studies we would need to retrieve and incorporate to result in a non-significant p-value was 147 studies (see also Borenstein, Hedges, Higgins, \& Rothstein, 2009).

\section{Coding Procedures}

Treatment dropout was defined as the percentage of patients who began treatment, but according to the author(s) dropped out prematurely, thus utilizing the author(s)' definition. For reliability and validity purposes we included only studies that reported dropout rates during treatment and not prior to treatment initiation.

Participant, therapist, treatment and study characteristics were coded (see Table 1 for details about coding of each of the variables). Eight participant characteristics included: client disorder, gender, age, race, marital status, employment, years of education and population. Eight treatment variables were comparison condition, treatment status, length of intervention, length of intervention in sessions, hours of intervention, format of treatment, treatment setting and description of treatment setting (as per Swift \& Greenberg, 2012). Two treatment provider variables regarding experience level: 1) experience level of ACT therapists, and 2) experience level of therapists in comparison groups. Finally, four study variables included: definition of dropout, study type, year of publication and region.

The second and third authors coded all variables separately and these were checked for accuracy by the first authors. There was a $95 \%$ agreement rate between coders with disagreements resolved via a consensus among the authors (for further coding details contact the authors). 


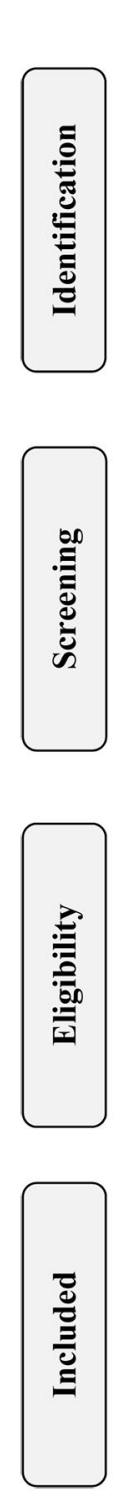

Records identified through database searching $(n=4171)$ (EBSCOhost $n=1245$, Google Scholar $n=1415$, Science Direct

$$
n=1511 \text { ) }
$$

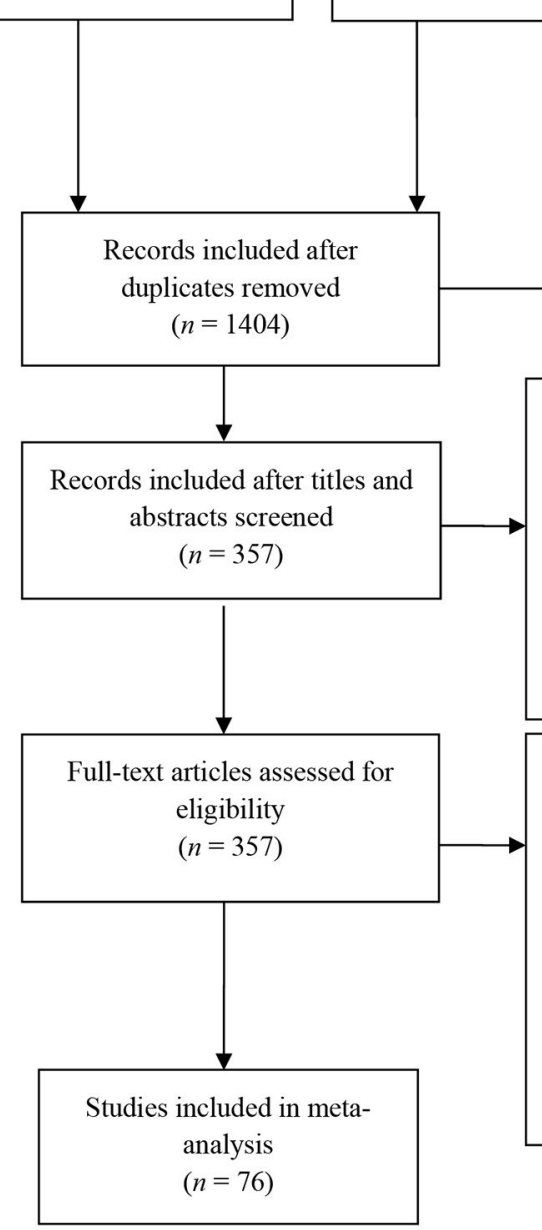

Additional records identified through metaanalysis and reviews $(n=228)$

(Veehof et al., 2011) $n=10$; Ost (2008) $n=$ 14; Powers et al. (2009) $n=18$; Ruiz (2012) $n=16$; Soo, Tate, $\&$ Lane-Brown (2011), $n=$ 5; Smout et al. (2012) $n=21$; Ruiz (2010) $n$

$=18$; Swain (2015) $n=10$; Lee et al. (2015) $n=10$; Ost (2014) $n=46$; Ong et al. (2018) $n=60$ )
Duplicates excluded $(n=2995)$

Records excluded $(n=1047)$ for the following reasons: no control group $(n=253)$, no information about dropouts ( $n=452)$, waiting list or other inactive group ( $n=$ $181)$, case studies $(n=107)$, language other than English $(n=$ 54)

Full-text articles excluded after review of full paper $(n=281)$ for the following reasons: case studies $(n=35)$, no control group $(n=89)$, no post- only follow-up $(n=2)$, no information about dropouts $(n=97)$, same population with other included study $(n=30)$, waiting list or other inactive control group

Figure 1. Flow chart of information from identification to inclusion of studies in this review. 
Table 1

Details Regarding the Coding of Each of the Variables

\section{Participant characteristics}

Client disorder

Anxiety disorder (including social phobia, public speaking anxiety, generalized anxiety disorder and obsessive compulsive disorder), depression, substance abuse or dependence, chronic pain (including fibromyalgia, osteoarthritis and headaches), eating pathology/disorder (including diabetes, obesity, weight problems and eating disorders), health conditions and chronic illnesses (i.e. Parkinson's disease, multiple sclerosis, brain injury, cancer and HIV), smoking, other health problems (stress, distress, physical activity, tinnitus, procrastination and sickness absence) and severe psychopathology (including borderline personality disorder, treatment resistant and psychosis)

$\begin{array}{ll}\text { Gender } & \text { Percentage of female participants in each study } \\ \text { Age } & \text { Average age in years of participants in each sample } \\ \text { Race } & \text { Percentage of White (including Caucasian, Australian and European), Black (including African } \\ & \text { American) and other (Hispanic, Latino, Asian American/ Pacific Islander, Native American, } \\ & \text { Alaskan American and American Indian/ Alaskan native) } \\ \text { Marital status } & \begin{array}{l}\text { Percentage of participants who were single (non-married, never married, divorced, separated or } \\ \text { widowed) vs. married (cohabiting, living with partner/spouse/family or in a relationship) }\end{array} \\ \text { Employment } & \begin{array}{l}\text { Percentage of participants who were working, either full-time or part-time } \\ \text { Years of education }\end{array} \\ & \begin{array}{l}\text { Participants' average number of completed education years in each study. In cases where the } \\ \text { mean number of education in years was not provided, we calculated this based on the data } \\ \text { reported. }\end{array} \\ \text { Population } & \text { Adults or children and adolescents }\end{array}$

\section{Treatment variables}

Comparison condition CBT, Treatment as Usual (TAU; studies in which TAU consisted of only administrating medication were coded as medication only), medication only (i.e., Medication Treatment as Usual plus Enhanced Assessment and Monitoring, Recommended Pharmacological Treatment, Specialty Medical Management, Methadone maintenance, Selective Serotonin Reuptake Inhibitors, Medical Treatment as Usual, Nicotine Replacement Treatment and Bupropion Regimen), other active treatment (i.e., Narcotics Anonymous, Applied Behavior Analysis, smokefree.gov, online discussion forum, usual care, counseling services, Workplace Dialogue Intervention, PresentCentered Therapy, physical exercise, Drug Counseling, Tinnitus Retraining Therapy and Expressive writing), component of CBT (including Progressive Relaxation Training, Systematic Desensitization, Applied Relaxation, Cognitive Therapy, Stress Inoculation Training, Relaxation Training) and education only (education, Befriending, Pedometer-based walking program)

Treatment status Providing any treatment/training to the comparison condition or not

Length of intervention Total length of treatment in weeks (in cases where months were reported, each month was calculated to equal 4 weeks)

Length of intervention Total number of treatment sessions

in sessions

Hours of intervention The overall duration of intervention in hours

Format of treatment Individual, self-help (including web-based and online format), group, or combination (group \& individual)

Treatment setting Description of Outpatient, inpatient or self-help (including web-based and online format)

treatment setting University affiliated clinic (psychology department training clinic and university counseling center), outpatient clinic affiliated with a hospital or medical school, public/community outpatient clinic, research/specialty clinic, private outpatient clinic/practice, therapy took place at participant's home (i.e., web-based/online intervention or self-help) and inpatient or residential treatment 


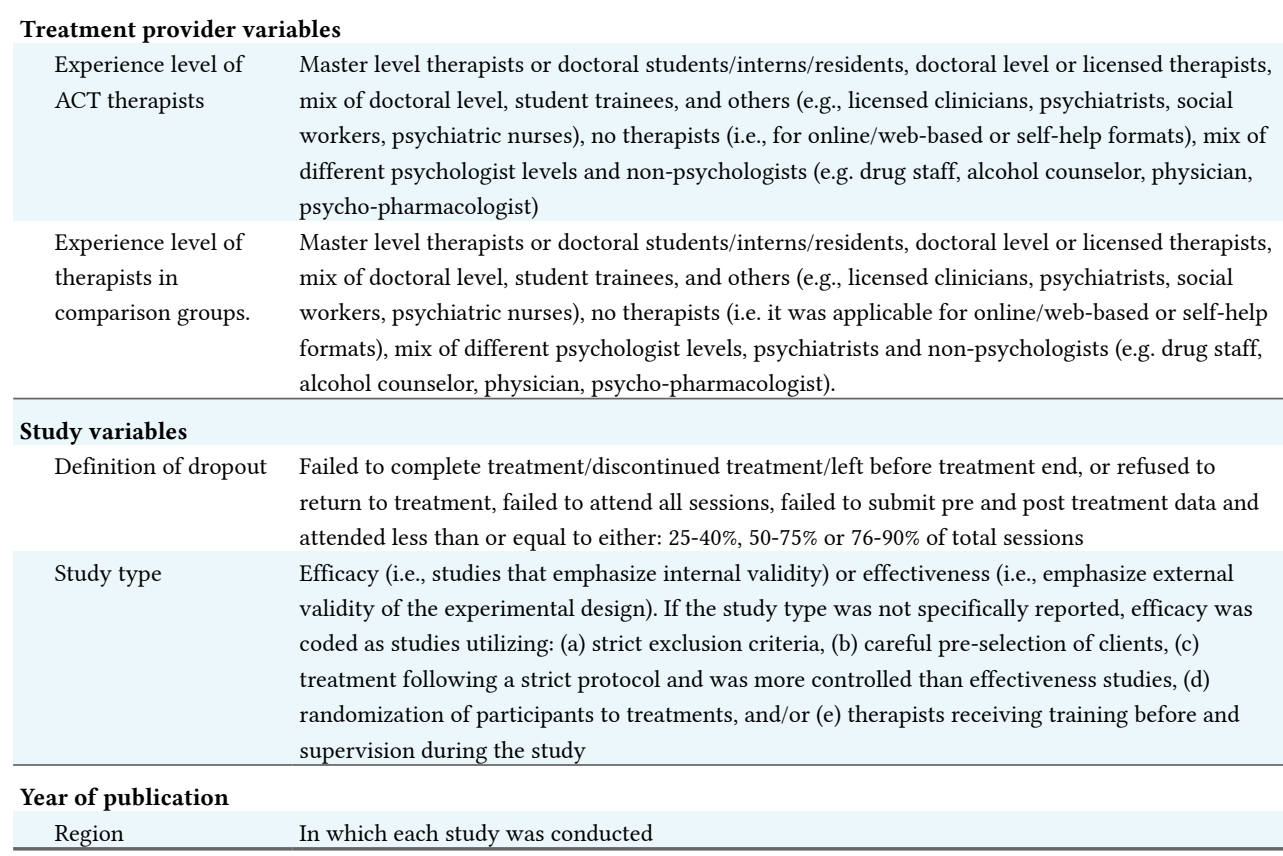

\section{Data Analysis}

First, the dropout rate for each study condition (ACT vs. comparison group) was calculated (i.e., the total number of patients who dropped out of each treatment group, out of the total number of patients included in each group). Then, the weighted average dropout rate (i.e., weighted dropout rate for each study condition based on the total number of patients included in the study) was computed for each of the 76 included studies. The number of participants dropped from each group was included in the Comprehensive Meta-Analysis software (CMA; version 2.0, Biostat, Englewood, NJ), along with the sample size of each group (treatment and comparison). Odds ratio was then computed. Odds ratios higher than 1 suggest that dropout rates are higher in the intervention versus the comparison condition (i.e., comparison group is better).

Random-effects models were used to estimate the effect size of rate ratio in the included studies, as the assumptions of random-effect models suggests that study characteristics influence the true effect of treatments, and that sampling error varies between studies (DerSimonian \& Kacker, 2007). The $Q$ statistic and the $I^{2}$ statistic were calculated. Random-effects models are considered appropriate when there is significant heterogeneity $(p$ $<.05)$ according to the $Q$ index, and when heterogeneity is high $(>75 \%)$ based on the $I^{2}$ index.

First, an unconditioned model without having any predictors or moderators was calculated using CMA, in order to detect the general rate ratio of dropouts between treat- 
ment and comparison conditions. In order to examine if the results of the general model were subject to biases related to the publication of studies with favorable outcomes, publication bias was investigated by assessing the asymmetries evident in a funnel plot, with the Egger's regression test (Egger, Smith, Schneider, \& Minder, 1997) and the Begg and Mazumdar test (Kendall's statistic). A stratified subgroup analyses was then run in order to test the moderating role of categorical study characteristics and meta-regression analyses to test the moderating role of continuous study characteristics. $Q$ statistic was calculated for the subgroup analyses, in order to examine if the differences detected between the mean effect sizes of the groups of studies with a particular characteristic were significant. The meta-regression analyses were computed using a general mixed-effects method-of-moments (Kacker, 2004) estimate for the inter-study variance $\tau^{2}$ (DerSimonian \& Kacker, 2007).

\section{Results}

\section{Characteristics of Reviewed Studies}

All identified studies were included in the meta-analysis; no structured qualitative assessment of the reviewed articles was performed. The large majority of included studies employed a randomized controlled trial design, or at least a controlled trial design. This suggests that all studies are at least of a moderate methodological quality (Petrisor \& Bhandari, 2007), and attempted to compare ACT to an active treatment comparison condition.

See Table 2 for characteristics of included studies. Most studies dealt with the treatment of anxiety $(n=14,18.4 \%)$ and chronic pain $(n=14,18.4 \%)$; and targeted adults $(n=$ $73,96.1 \%)$ using a group treatment format $(n=34,44.7 \%)$. ACT was compared mostly with TAU $(n=17,22.4 \%)$ and CBT $(n=17,22.4 \%)$. Most studies were delivered in an outpatient setting $(n=60,78.9 \%)$ and participants were most frequently recruited via community advertisements $(n=21,27.6 \%)$. Treatment in ACT groups was delivered mostly by psychologists of various training levels $(n=19,25 \%)$ and licensed or doctoral level psychologists $(n=15,19.7 \%)$. In comparison group treatment was provided mostly by a mix of doctoral level, student trainees and others $(n=15,19.7 \%)$ and a mix of psychologists with different training levels $(n=13,17.1 \%)$. The most frequent definition of dropout was "failed to complete treatment, left treatment prior to its end, or refused to return to treatment" ( $n=53,69.7 \%)$. Finally, efficacy-type studies $(n=42,55.3 \%)$ were more than effectiveness-type studies $(n=34,44.7 \%)$. 


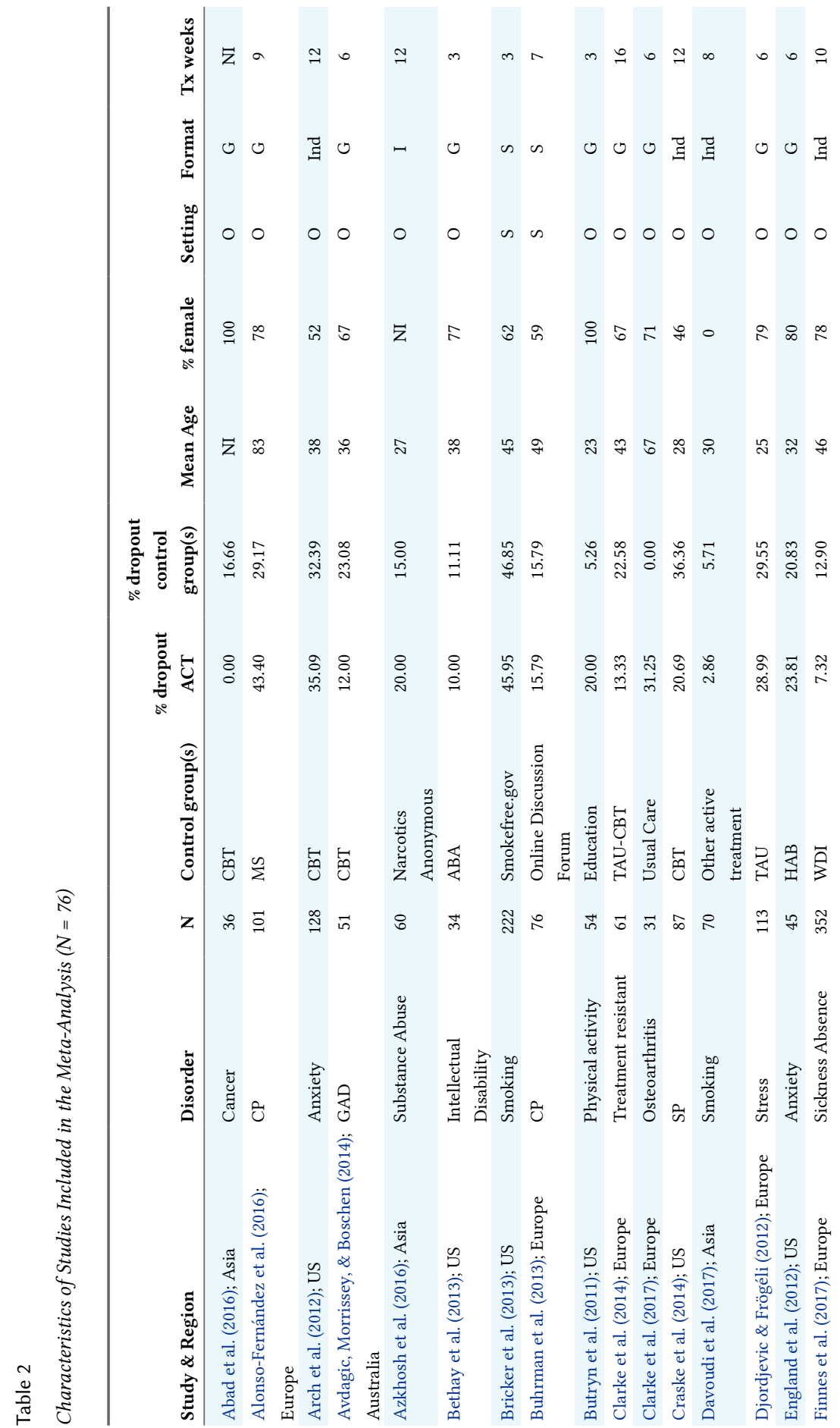




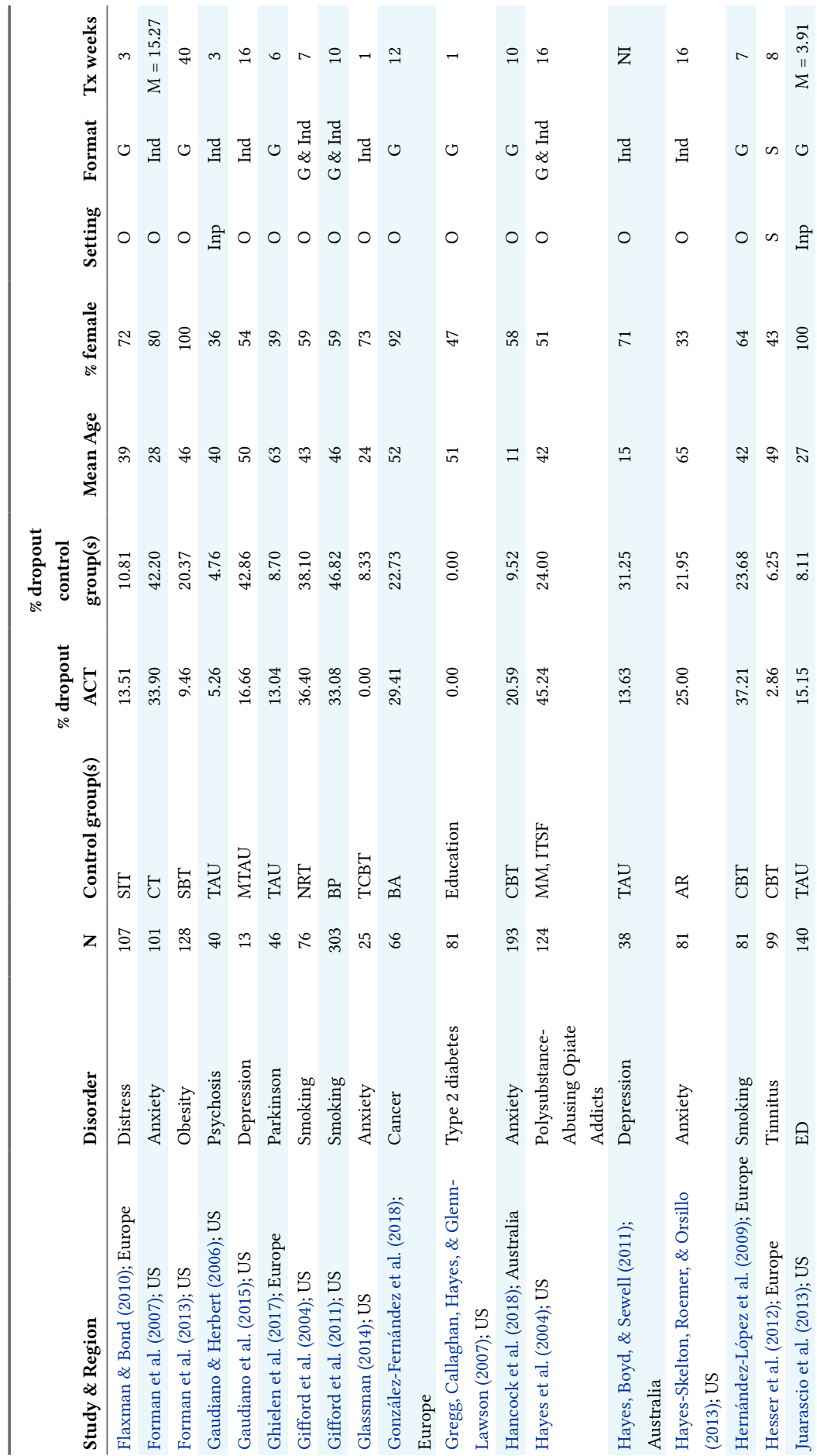




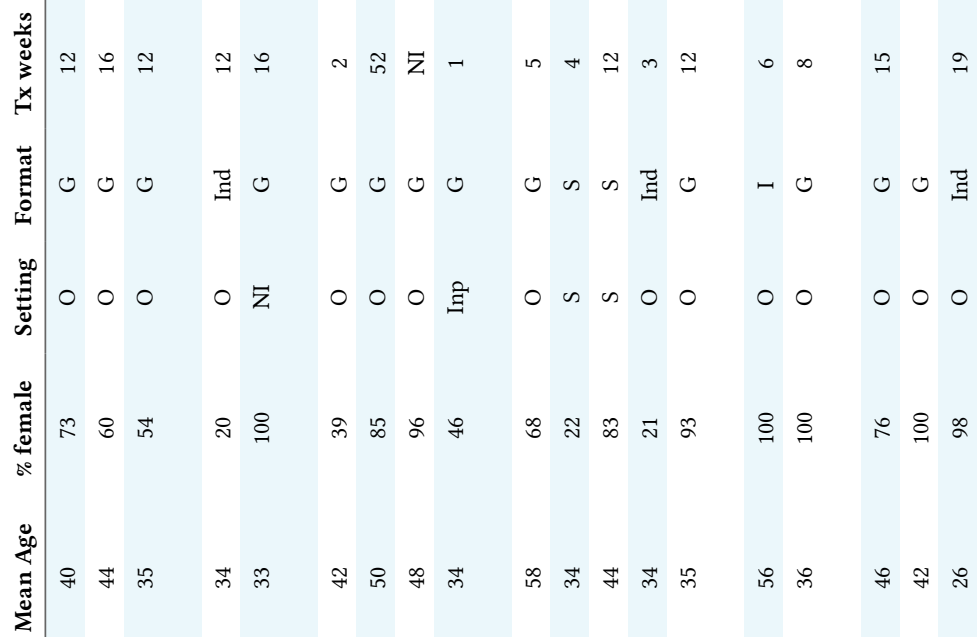

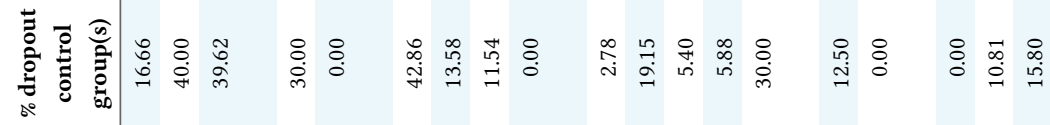

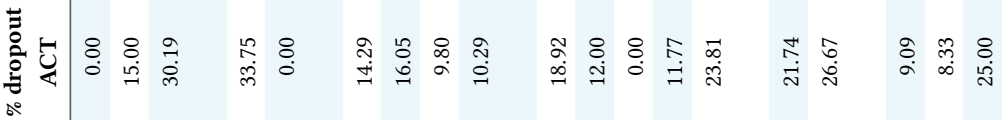

$\hat{0}$
$\vdots$
0
0
0
$\vdots$
0
0
0

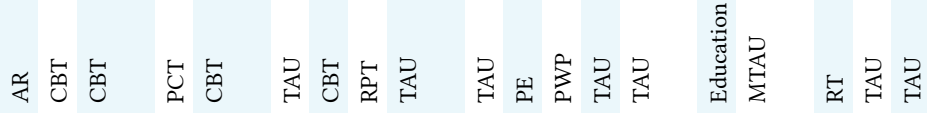

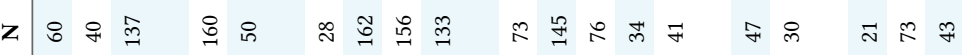
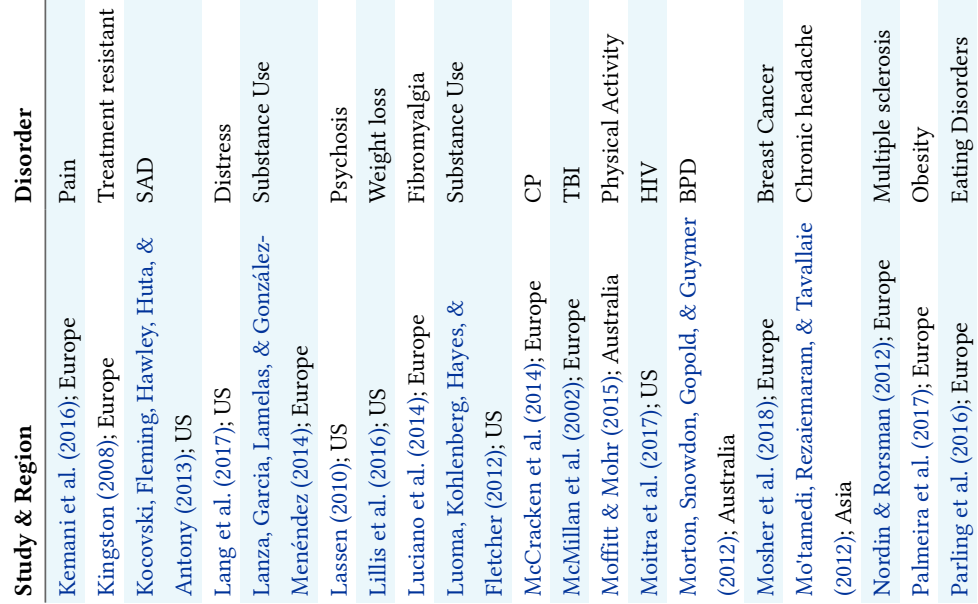


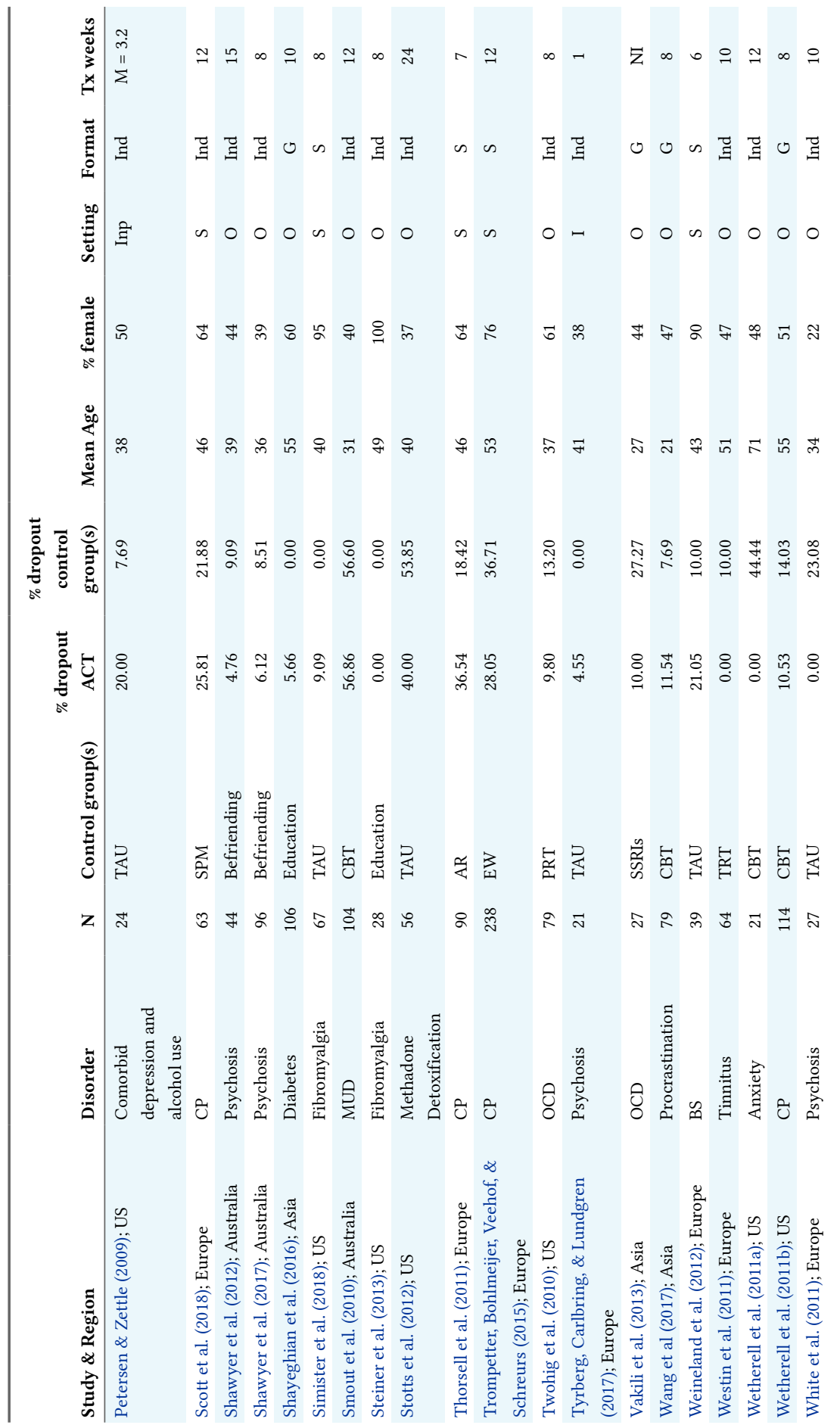




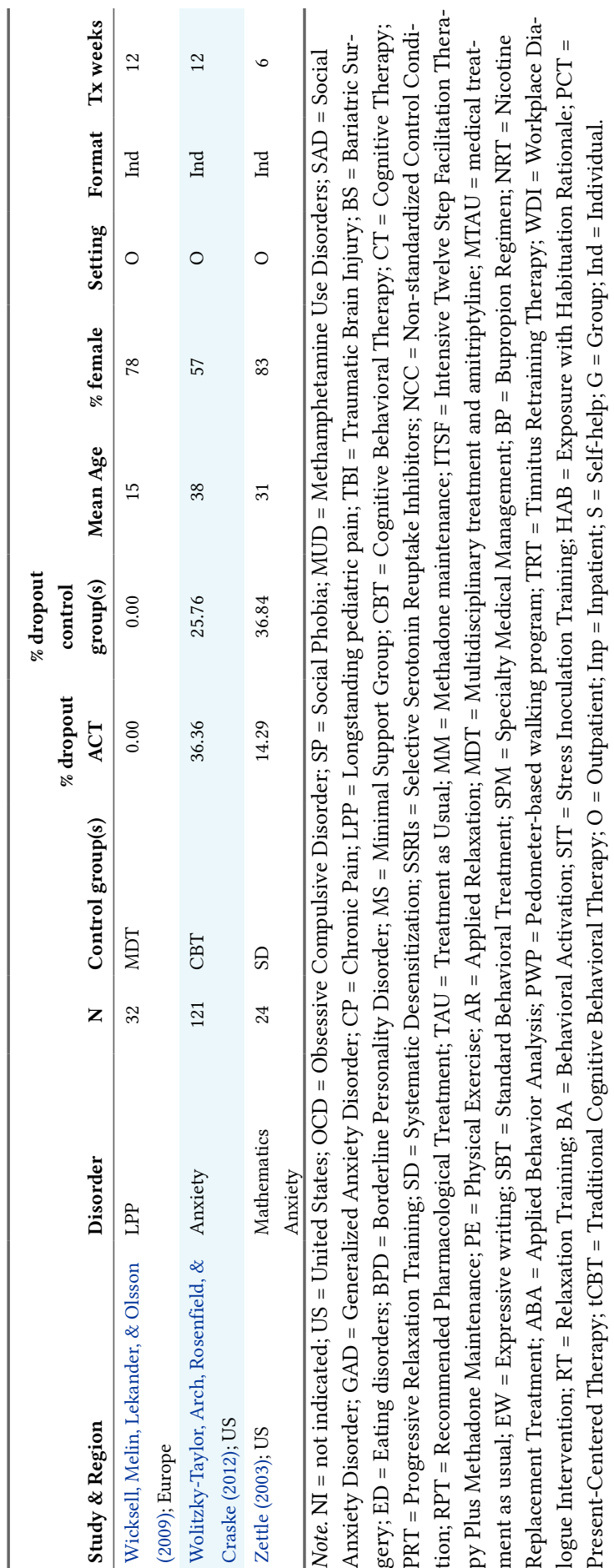


Regarding reasons reported for dropout, the majority of studies did not report data about client variables separately for dropout and completers. Of the 65 studies presenting drop-outs in the ACT condition, only 27 studies (41.54\%) reported reasons for dropout. Regard-ing comparisons, all participants completed treatment in 11 studies, whereas for the re-maining 65 studies with dropouts, only 30 (45.15\%) reported dropout reasons. For ACT, the most frequently reported reasons for dropout were: lost contact ( $n=15,55.55 \%)$, per-sonal $(n=12,44.44 \%)$, transportation difficulties $(n=10,37.04 \%)$ and therapy factors ( $n=9,33.33 \%)$. However, for comparison condition(s) the main reasons for dropout were: lost contact $(n=19,63.33 \%)$, therapy factors $(n=11,36.67 \%)$ and time demands $(n=10$, $33.33 \%$ ). For percentages of clients reporting each of the reasons for the included studies, see Appendix A in Supplementary Materials.

\section{Dropout Rates}

Across all studies and comparison conditions, the overall weighted mean dropout rate was $17.95 \%, 95 \%$ CI [15.12, 20.77]. ACT trials reported an average dropout rate of $17.35 \%$, 95\% CI [14.33, 20.37] and comparison conditions reported an average dropout rate of $18.62 \%, 95 \%$ CI [15.29, 21.96]. In the CMA, the unconstrained model with the 76 studies of ACT vs. comparison conditions, showed that the heterogeneity detected using the fixedeffects model was very small and non-significant, with $\mathrm{Q}(75)=79.371, p=.343, \mathrm{I}^{2}=$ $5.507 \%$. It was thus justifiable to hypothesize that the random errors among the studies were not considerably different and that fixed-effects models could be followed. Despite dropout rates in ACT appearing to be lower than in comparison groups when examining the overall weighted mean dropout rate the difference did not reach statistical significance, as the point estimate of the odds ratio and its confidence intervals included value 1 (i.e., equal odds/risk to dropout) with $O R=0.931,95 \%$ CI $[0.809,1.070], z=-1.011$, $p=.312$; see Appendix B in Supplementary Materials). The funnel plot for the investigation of publication bias in the meta-analysis (see Appendix B in Supplementary Materials) indicated no asymmetry, suggesting that there was no statistically significant publication bias, with Egger test $t(74)=0.591,95 \%$ CI $[-0.617,0.334], p=.556)$ or the Begg and Mazumdar Kendall's tau, with $\tau=-0.079, p=.313$.

\section{Quantitative Synthesis of the Findings of the Reviewed Studies: Meta-Analysis}

\section{Participant Moderators}

Eight participant variables were first examined as moderators of therapy dropout (see Table 3). 


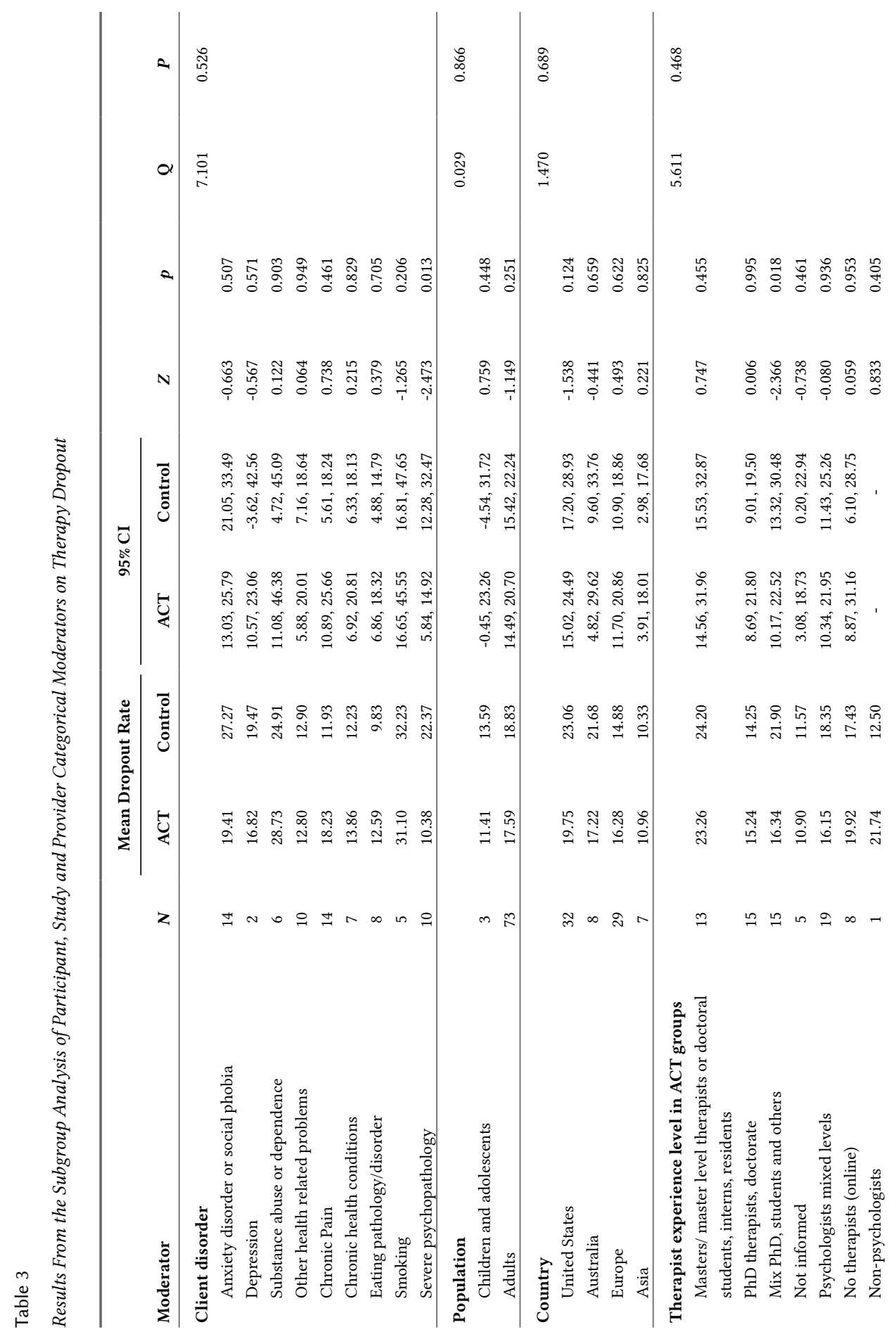




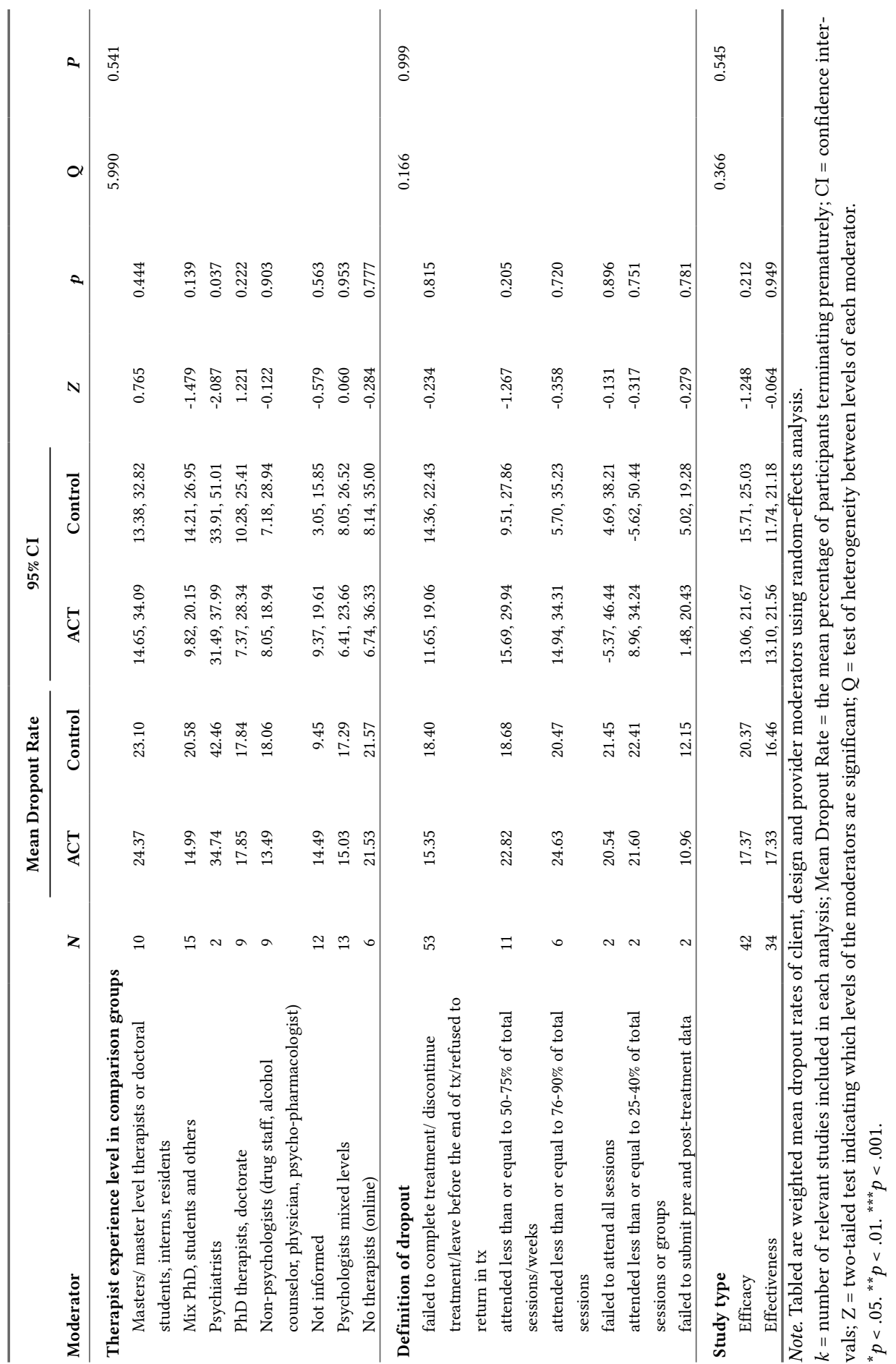


Regarding categorical moderators, there were no significant differences between subgroups. This was expected as heterogeneity among the studies was very small and the studies were generally favoring ACT groups but this finding did not reach statistical significance. However, separate investigation of the effect sizes in each subgroup of studies showed that a significant finding was noted in the subgroup analysis for the type of disorder under investigation (see Appendix C in Supplementary Materials); where in studies with a population with a severe psychopathology (i.e., borderline personality disorder, treatment resistant and psychosis) the dropouts were significantly lower in ACT groups compared to comparisons $(O R=0.473, z=-2.473, p=.01)$. In terms of the six participant continuous moderators, meta-regression analyses based on the odds ratio using a method-of-moments estimation showed that none of them (gender, marriage, ethnicity, employment and mean age) were independent predictors of the effect size.

\section{Treatment Moderators}

Eight treatment variables were tested as moderators of dropout rate (see Table 4 for categorical variables). Subgroup analyses of treatment setting showed again non-significant between-group differences for all the variables examined. However, a statistically significant effect was noted in the subgroup analysis using the recruitment setting, as having recruited the population from a public outpatient clinic and/or community advertisements resulted in significantly lower odds of the population to drop out from ACT groups compared to comparison groups, $O R=0.652, z=-2.985, p=.003$. No significant differences were found among the rest of the examined treatment moderators and no other significant effect sizes in specific subgroups were noticed.

\section{Provider and Study Moderators}

Only a small amount of studies reported therapist gender, age, and ethnicity, deeming it impossible to analyze them as moderators. The experience levels of the therapists in ACT and comparison groups showed non-significant differences. However, in the subgroup analysis of the ACT therapists' experience level a significant effect size was found for the subgroup of therapists from mixed experience levels, including doctoral level, student trainees, and others (e.g., licensed clinicians, psychiatrists, social workers, psychiatric nurses). The odds on dropout from ACT groups were significantly lower than from comparison groups when the ACT therapists consisted of a multi-level and multi-domain team, with $O R=0.734, z=-2.366, p=.018$. Also, in the subgroup analysis of the comparison groups' therapists a significant effect favoring ACT groups was found in the subgroup of psychiatrists. When the comparison groups had psychiatrists as the main and only therapists, then participants had significantly higher odds to dropout, compared to ACT groups, with $O R=0.638, z=-2.087, p=.037$. Regarding study moderators, subgroup analyses based on region and type of study, or when examining the predictive ability of the year of publication in meta-regression analyses showed no significant results. 


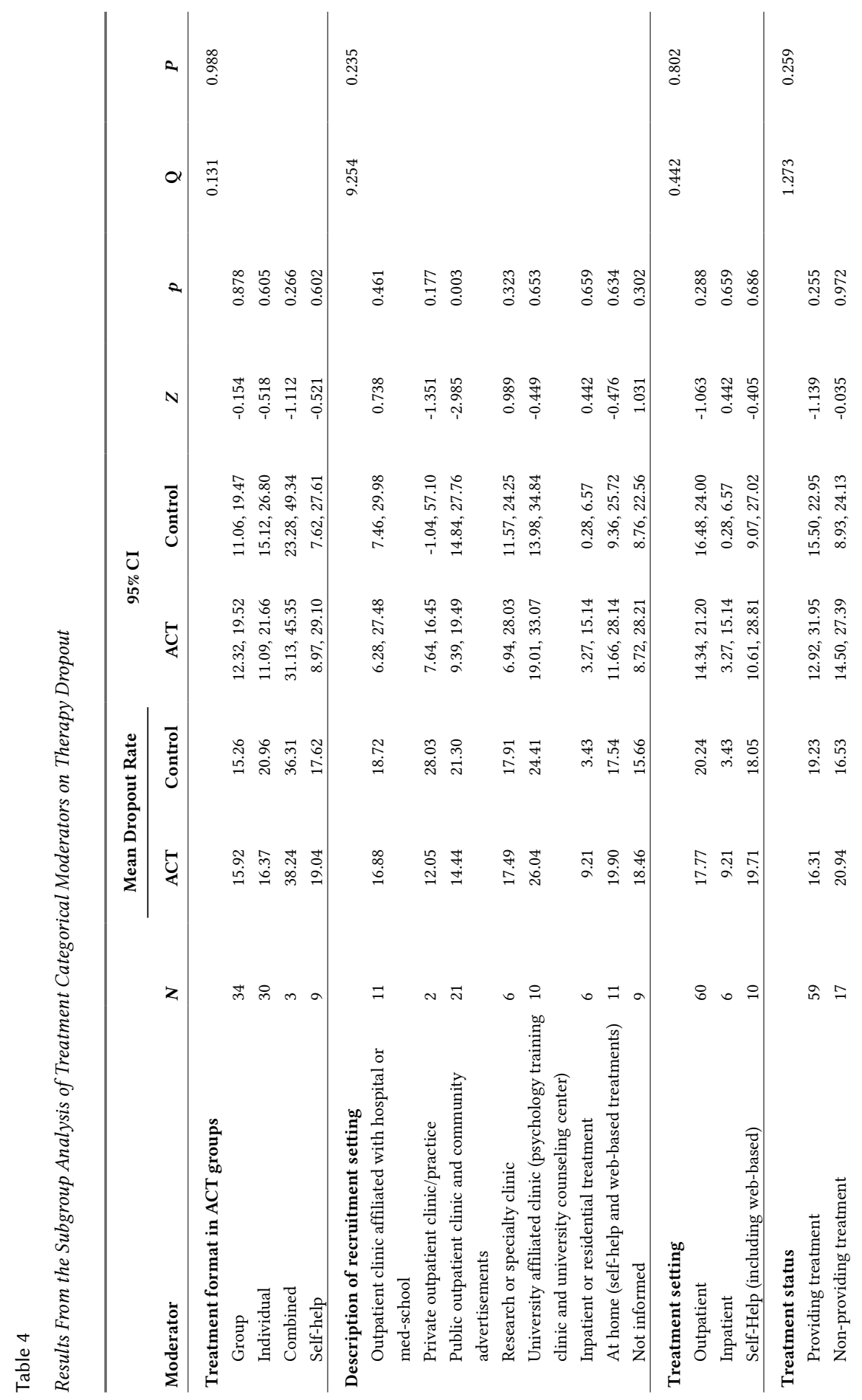




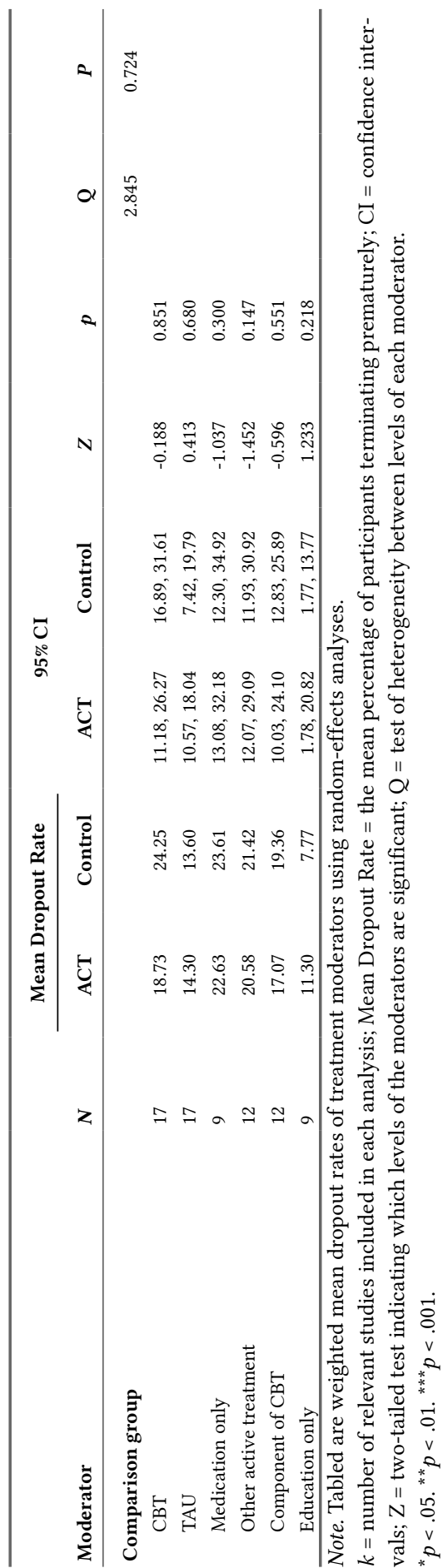




\section{Sensitivity Analyses}

We performed sensitivity analyses based on decisions taken before, or based on the previous findings of the meta-analysis. The exclusion of the three studies that consisted of dissertations, showed that the main effect did not change significantly, with $O R=0.951$, $95 \%$ CI $[0.826,1.094], z=-0.705, p=.481$, even though heterogeneity was slightly reduced, with $\mathrm{Q}(72)=73.808, p=.419, \mathrm{I}^{2}=2.450$. The next sensitivity analysis concerned the exclusion of studies with very wide confidence intervals of the odds ratio and showed again no change of the main effect. Later on, we investigated the main effect when excluding recent papers (2016-2018), as the meta-regression analysis for the predictive ability of the year of publication showed a trend to significance. This sensitivity analysis (see Appendix D in Supplementary Materials) showed that the main effect became marginally significant, with $O R=0.852,95 \%$ CI [0.727, 0.998], $z=-1.984, p=.047$, even though heterogeneity was slightly increased but remained at small levels, with $Q(54)=60.961$, $p=.240, \mathrm{I}^{2}=11.418$. The finding of the sensitivity analysis concerning the year of publication suggested that when considering research done before 2016, the dropouts from ACT groups were significantly lower than from active comparison groups.

\section{Discussion}

Treatment dropout is an important parameter impacting treatment outcomes (Barrett et al., 2008; Wierzbicki \& Pekarik, 1993). Despite the acknowledgement of the importance of considering dropout rates and how these influence treatment effectiveness conclusions, this phenomenon has not been extensively examined. This paper aimed to investigate the phenomenon of dropout in a relatively newly developed therapeutic approach, Acceptance and Commitment Therapy. Compared to other cognitive behavioral approaches, ACT presents with advances in improving client engagement to treatment, emphasizes the therapeutic relationship, and provides meaning for any changes to be made during treatment, postulated to be associated with more participant engagement. Indeed, change in values has been found to precede changes in suffering (Gloster et al., 2017). As such, we aimed to examine if those advances presented in ACT could overcome some of the treatment acceptability criticisms presented with older generations of interventions, which may have contributed to increased dropout rates from psychological treatments. However, the overall dropout rate was not significantly different between ACT and comparison groups in the present meta-analysis.

As noted by others, we found that there is no consensus regarding the definition employed by investigators. We adopted a broad definition of treatment dropout, utilizing what was reported by each study author and particularly considering dropouts to be the percentage of cases of individuals who began treatment but did not complete it as intended by its developer. Based on this definition, the yielded overall dropout rate across all 
studies included in this meta-analysis was $17.95 \%$, which is comparable to recent previously meta-analytically reported rates (i.e., 19.70\%; Swift \& Greenberg, 2012). For ACT, the calculated mean dropout rate was $17.35 \%$. This is similar again to the rates reported by Galloway-Williams, Martin, Clum, and Cooper (2013) and Ong et al. (2018) for ACT. When including all possible reasons and comparing across all comparison conditions, the dropout rate was not significantly different (18.62\%) from ACT groups. However, the reason why individuals terminate their treatment prematurely needs to be considered in relation to dropout rates.

Unfortunately, the majority of examined studies did not include dropout reasons, limiting our ability to draw conclusions regarding the reasons for dropout. Despite the limited number of studies presenting reasons for dropouts, some important differences between ACT and other groups were identified. For example, most individuals who dropped out from ACT groups did so because of lost contact and for (unrelated to therapy) personal reasons. Dropout reasons in comparison conditions however, included additionally therapy-related reasons (e.g., not satisfied with the treatment or feeling that the therapy was too time consuming). In particular, when ACT was compared to CBT, the most frequent reason for dropping out of CBT was therapy factors (i.e., of the 5 studies who reported reasons for dropout from CBT, all of them mentioned therapy factors). In contrast, in ACT, the reasons of time demands, transportation, personal and therapy were equally reported. This is in line with findings reported by Karekla (2004) who found differences in the timing of dropout in relation to the treatment components between tCBT and ACT participants. The pattern of dropout in tCBT was linked to the initiation of exposure whereas the same pattern was not found for those in the ACT condition (where individuals who dropped out did so for unrelated reasons to treatment and discontinued at different time points and not before exposure was introduced). These findings lend support to the idea that ACT may be a more acceptable treatment choice over previous waves of tCBT, and may better prepare (e.g., via use of values) individuals to engage and ultimately benefit from even the most difficult of treatment content (e.g., exposure to feared stimuli; see also Gloster et al., 2014, 2015). In the future, researchers are advised to examine and report upon the timing and reasons for dropout.

In this review, we found that ACTs' premature termination rates were lower for dealing with certain types of psychopathology (severe psychopathology). This finding may highlight the important addition of ACT skills for severe psychopathologic conditions; however this needs to be further explored. Interestingly, participants' age did not moderate dropout rates, suggesting that all age groups result in similar dropout rates. This is a divergence from the Swift and Greenberg (2012) meta-analysis, where younger individuals had higher dropout rates (Barrett et al., 2008).

The subgroup analyses based on the description of the treatment setting showed that dropout rates from ACT groups were lower for studies in which the treatment was delivered in a public outpatient clinic and population was recruited by community advertise- 
ments. However, one should note that these studies were highly heterogeneous, including participants with anxiety disorders, eating disorders, substance abuse, other health problems, chronic pain, health conditions/chronic illnesses, smoking, severe psychopathology (i.e., BPD, psychosis, treatment resistant), and depression. Additionally, in most of these studies the comparison condition was not another psychologically active intervention (i.e., in $57 \%$ of them the comparison group was treatment as usual, medication only and education). Due to the high heterogeneity of these studies, this finding should be interpreted with caution and further examined in the future.

In terms of provider moderators, experience level of providers in ACT and comparison groups were significantly related to dropout rates. Specifically, when treatment was delivered by a multi-level and multi-domain team, ACT had lower dropout rates than comparison conditions. This is a divergence from the studies of Ong et al. (2018) and Swift and Greenberg (2012), who reported no significant results when treatment was delivered by multidisciplinary teams. In particular, in the study of Ong et al. (2018), ACT had higher dropout rates than comparison groups when treatment was administered by master's-level clinicians/therapists whereas in the study of Swift and Greenberg (2012) dropout rates were higher when the treatment was provided by trainees. Differences between these studies may be a result of the definition used for therapist experience level, therefore more research is needed in this domain to be able to conclusively make recommendations as to the level of experience or the consistency of the therapeutic team that leads to higher effect sizes. For the guidance of future researchers examining dropouts in treatments, a checklist of definitions and variables to be collected which can be utilized before, during and while reporting their findings, to ensure that adequate information regarding dropouts is available, is presented in Appendix E (see Supplementary Materials).

\section{Limitations}

This study has several limitations that need to be considered in the interpretation of findings. First, the inclusion criteria were made broad enough in order to include a large number of studies. All age groups were included; as well as various psychopathological and non-psychopathological problems, and studies combining ACT with other interventions or medication. Though we attempted to deal with this heterogeneity in the disorders, interventions, populations and age conditions by examining moderators of interest, this heterogeneity may have still affected the clarity of any differences between ACT and comparison groups on dropout rates.

A second limitation may be related to the coding procedure. Specifically, for the variable of comparison condition, when a study had two comparison conditions we selected to compare only the active treatment (e.g., CBT) and excluded the inactive comparison condition (e.g., wait-list). A third limitation has to do with reasons reported for dropouts. Specifically, the majority of studies did not report dropout reasons, making conclusions about true reasons for dropout impossible or biased for the studies that reported these 
reasons. In order to further elucidate the phenomenon of treatment dropout, future studies should examine and report reasons why participants drop out as well as the timing when this occurs. Finally, in our meta-analysis it was not possible to carry out a comparison between the demographic characteristics of dropouts and completers due to insufficient data provided by studies. We would like to encourage researchers to ensure that they report information separately for completers and dropouts so as to facilitate further understanding into the phenomenon of dropout.

\section{Clinical Implications}

This review examined dropout rates of a third wave CBT intervention in a range of disorders, populations, ages and comparison conditions. Our findings show that overall dropout rates between ACT and comparison conditions were not found to differ significantly. Additionally, moderation analyses suggest that experience level of therapists in ACT and comparison conditions, description of treatment setting, and client diagnosis are associated with an increased likelihood of dropout. Therefore, interventions aiming to lower attrition should plan a-priori how to better engage users belonging to these groups.

Our findings suggest that ACT may present some potential advances for improving client engagement and retention, such as emphasizing that any behavior change needs to be linked with the persons' values, or it may include more interesting treatment content through the use of metaphors and experiential exercises. However, more research is still needed prior to being able to assertively make these conclusions.

\section{Future Research}

The findings of the present study offer possible hypotheses about which therapeutic processes are associated with client retention. However, more studies are needed that will examine particular reasons for premature treatment termination, timing when this phenomenon occurs and how it may be linked to specific treatment components, and associated variables in third wave treatments.

Moderators of the dropout effect for different therapeutic approaches are critical in that they illuminate areas that may still have potential for improvement in the context of an otherwise effective intervention. This needs to be further examined. For example, even if ACT has lower dropout rates than some comparison conditions overall, but females drop out more from ACT than comparison conditions, then ACT may need to consider how females are being engaged in the intervention and attempt to find ways to improve engagement (e.g., maybe more gender sensitive metaphors). Additionally, common vs. specific factors in the psychotherapies being examined and in relation to how these may affect dropout also need to be examined. Researchers are encouraged to examine and report the reasons for dropout when a person discontinues the treatment prematurely. Further understanding of these reasons should allow us to examine whether it is dis- 
satisfaction with the common factors (e.g., therapeutic alliance, expectations, cultural adaptations, empathy) that contribute to premature discontinuation or whether dropout is related to specific factors (e.g., specific ingredients of the intervention provided). It is essential that participant engagement and premature termination continue to serve as topics of exploration in the clinical psychology arena, so as to improve the effectiveness of interventions, decrease treatment dropout rates, and enhance the possible treatment effects for participants.

Funding: The authors received no financial support for the research, authorship, and/or publication of this article.

Competing Interests: The authors declare no conflicts of interest.

Acknowledgments: The authors have no support to report.

Data Availability: Datasets for the studies are freely available (see the Supplementary Materials section).

\section{Supplementary Materials}

The following data and materials are available for this study (for access see Index of Supplementary Materials below):

\section{Via the PsychArchives repository:}

- Appendix A: Percentages of clients reporting each of the reasons for the included studies

- Appendix B: Forest and funnel plots of included studies

- Appendix C: Forest plot of subgroup analyses based on the type of disorder under investigation

- Appendix D: Sensitivity analysis for the year of publication

- Appendix E: Checklist of definitions and variables to be collected in order to properly document dropouts

Via the International Prospective Register of Systematic Reviews (PROSPERO):

- Preregistered protocol (CRD42017068456) of the current study

\section{Index of Supplementary Materials}

Karekla, M., Konstantinou, P., Ioannou, M., Kareklas, I., \& Gloster, A. T. (2019). Supplementary materials to "The phenomenon of treatment dropout, reasons and moderators in Acceptance and Commitment Therapy and other active treatments: A meta-analytic review". PsychOpen. https://doi.org/10.23668/psycharchives.2594

Karekla, M., Konstantinou, P., Ioannou, M., Kareklas, I., \& Gloster, A. T. (2017, July 7). Treatment drop-out in acceptance and commitment therapy compared to other treatments: A systematic 
review and meta-analysis. (PROSPERO 2017 CRD42017068456). PROSPERO.

https://www.crd.york.ac.uk/PROSPERO/index.php

\section{References}

Note. Asterisk $\left(^{*}\right)$ marks references of studies included in the meta-analysis.

*Abad, A. N. S., Bakhtiari, M., Kashani, F. L., \& Habibi, M. (2016). The comparison of effectiveness of treatment based on acceptance and commitment with cognitive-behavioral therapy in reduction of stress and anxiety in cancer patients. International fournal of Cancer Research and Prevention, 9(3), 229-246.

*Alonso-Fernández, M., López-López, A., Losada, A., González, J. L., \& Wetherell, J. L. (2016). Acceptance and commitment therapy and selective optimization with compensation for institutionalized older people with chronic pain. Pain Medicine, 17(2), 264-277. https://doi.org/10.1111/pme.12885

*Arch, J. J., Eifert, G. H., Davies, C., Vilardaga, J. C., Rose, R. D., \& Craske, M. G. (2012). Randomized clinical trial of CBT vs. ACT for mixed anxiety disorders. Fournal of Consulting and Clinical Psychology, 80, 750-765. https://doi.org/10.1037/a0028310

A-Tjak, J. G. L., Davis, M. L., Morina, N., Powers, M. B., Smits, J. A. J., \& Emmelkamp, P. M. G. (2015). A meta-analysis of the efficacy of ACT for clinically relevant mental and physical health problems. Psychotherapy and Psychosomatics, 84(1), 30-36. https://doi.org/10.1159/000365764

*Avdagic, E., Morrissey, S. A., \& Boschen, M. J. (2014). A randomised controlled trial of acceptance and commitment therapy and cognitive-behaviour therapy for generalised anxiety disorder. Behaviour Change, 31(2), 110-130. https://doi.org/10.1017/bec.2014.5

*Azkhosh, M., Farhoudianm, A., Saadati, H., Shoaee, F., \& Lashani, L. (2016). Comparing acceptance and commitment group therapy and 12-steps Narcotics Anonymous in addict's rehabilitation process: A randomized controlled trial. Iranian fournal of Psychiatry, 11(4), 244-249.

Bados, A., Balaguer, G., \& Saldaña, C. (2007). The efficacy of cognitive-behavioral therapy and the problem of drop-out. fournal of Clinical Psychology, 63, 585-592.

https://doi.org/10.1002/jclp.20368

Barrett, M. S., Chua, W. J., Crits-Christoph, P., Gibbons, M. B., \& Thompson, D. (2008). Early withdrawal from mental health treatment: Implications for psychotherapy practice. Psychotherapy, 45, 247-267. https://doi.org/10.1037/0033-3204.45.2.247

*Bethay, J. S., Wilson, K. G., Schnetzer, L. W., Nassar, S. L., \& Bordieri, M. J. (2013). A controlled pilot evaluation of acceptance and commitment training for intellectual disability staff. Mindfulness, 4(2), 113-121. https://doi.org/10.1007/s12671-012-0103-8

Borenstein, M., Hedges, L. V., Higgins, J., \& Rothstein, H. R. (2009). Publication bias. In M. Borenstein, L. V. Hedges, J. P. T. Higgins, \& H. R. Rothstein (Eds.), Introduction to meta-analysis (pp. 277-292). Hoboken, NJ, USA: Wiley. https://doi.org/10.1002/9780470743386.ch30 
*Bricker, J., Wyszynski, C., Comstock, B., \& Heffner, J. L. (2013). Pilot randomized controlled trial of web-based acceptance and commitment therapy for smoking cessation. Nicotine \& Tobacco Research, 15(10), 1756-1764. https://doi.org/10.1093/ntr/ntt056

*Buhrman, M., Skoglund, A., Husell, J., Bergström, K., Gordh, T., Hursti, T., . . Andersson, G. (2013). Guided internet-delivered acceptance and commitment therapy for chronic pain patients: A randomized controlled trial. Behaviour Research and Therapy, 51(6), 307-315. https://doi.org/10.1016/j.brat.2013.02.010

*Butryn, M. L., Forman, E., Hoffman, K., Shaw, J., \& Juarascio, A. (2011). A pilot study of acceptance and commitment therapy for promotion of physical activity. Fournal of Physical Activity and Health, 8(4), 516-522. https://doi.org/10.1123/jpah.8.4.516

${ }^{*}$ Clarke, S., Kingston, J., James, K., Bolderston, H., \& Remington, B. (2014). Acceptance and commitment therapy group for treatment-resistant participants: A randomized controlled trial. fournal of Contextual Behavioral Science, 3(3), 179-188. https://doi.org/10.1016/j.jcbs.2014.04.005

${ }^{*}$ Clarke, S. P., Poulis, N., Moreton, B. J., Walsh, D. A., \& Lincoln, N. B. (2017). Evaluation of a group acceptance commitment therapy intervention for people with knee or hip osteoarthritis: A pilot randomized controlled trial. Disability and Rehabilitation, 39(7), 663-670.

https://doi.org/10.3109/09638288.2016.1160295

${ }^{*}$ Craske, M. G., Niles, A. N., Burklund, L. J., Wolitzky-Taylor, K. B., Vilardaga, J. C. P., Arch, J. J., . . Lieberman, M. D. (2014). Randomized controlled trial of cognitive behavioral therapy and acceptance and commitment therapy for social phobia: Outcomes and moderators. fournal of Consulting and Clinical Psychology, 82(6), 1034-1048. https://doi.org/10.1037/a0037212

*Davoudi, M., Omidi, A., Sehat, M., \& Sepehrmanesh, Z. (2017). The effects of acceptance and commitment therapy on man smokers' comorbid depression and anxiety symptoms and smoking cessation: A randomized controlled trial. Addiction \& Health, 9(3), 129-138.

DerSimonian, R., \& Kacker, R. (2007). Random-effects model for meta-analysis of clinical trials: An update. Contemporary Clinical Trials, 28(2), 105-114. https://doi.org/10.1016/j.cct.2006.04.004

${ }^{*}$ Djordjevic, A., \& Frögéli, E. (2012). Mind the gap: ACT for preventing stress-related ill-health among future nurses. A randomized controlled trial (Graduate thesis). Stockholm, Sweden: Institute for Clinical Neuroscience, Karolinska Institute.

Egger, M., Smith, G. D., Schneider, M., \& Minder, C. (1997). Bias in meta-analysis detected by a simple, graphical test. BMF, 315(7109), 629-634. https://doi.org/10.1136/bmj.315.7109.629

*England, E. L., Herbert, J. D., Forman, E. M., Rabin, S. J., Juarascio, A., \& Goldstein, S. P. (2012). Acceptance-based exposure therapy for public speaking anxiety. Journal of Contextual Behavioral Science, 1(1-2), 66-72. https://doi.org/10.1016/j.jcbs.2012.07.001

*Finnes, A., Ghaderi, A., Dahl, J., Nager, A., \& Enebrink, P. (2017). Randomized controlled trial of acceptance and commitment therapy and a workplace intervention for sickness absence due to mental disorders. fournal of Occupational Health Psychology, 24(1), 198-212.

https://doi.org/10.1037/ocp0000097 
${ }^{*}$ Flaxman, P. E., \& Bond, F. W. (2010). A randomised worksite comparison of acceptance and commitment therapy and stress inoculation training. Behaviour Research and Therapy, 48(8), 816-820. https://doi.org/10.1016/j.brat.2010.05.004

Fletcher, L., \& Hayes, S. C. (2005). Relational frame theory, ACT, and a functional analytic definition of mindfulness. Fournal of Rational-Emotive and Cognitive-Behavior Therapy, 23, 315-336. https://doi.org/10.1007/s10942-005-0017-7

*Forman, E. M., Butryn, M. L., Juarascio, A. S., Bradley, L. E., Lowe, M. R., Herbert, J. D., \& Shaw, J. A. (2013). The mind your health project: A randomized controlled trial of an innovative behavioral treatment for obesity. Obesity, 21(6), 1119-1126. https://doi.org/10.1002/oby.20169

*Forman, E. M., Herbert, J. D., Moitra, E., Yeomans, P. D., \& Geller, P. A. (2007). A randomized controlled effectiveness trial of acceptance and commitment therapy and cognitive therapy for anxiety and depression. Behavior Modification, 31(6), 772-799. https://doi.org/10.1177/0145445507302202

Galloway-Williams, N., Martin, E. C., Clum, G. A., \& Cooper, L. D. (2013). A meta-analysis of acceptance and commitment therapy for psychological disorders. Unpublished manuscript.

${ }^{*}$ Gaudiano, B. A., Busch, A. M., Wenze, S. J., Nowlan, K., Epstein-Lubow, G., \& Miller, I. W. (2015). Acceptance-based behavior therapy for depression with psychosis: Results from a pilot feasibility randomized controlled trial. Fournal of Psychiatric Practice, 21(5), 1538-1145. https://doi.org/10.1097/PRA.0000000000000092

${ }^{*}$ Gaudiano, B. A., \& Herbert, J. D. (2006). Acute treatment of inpatients with psychotic symptoms using ACT: Pilot results. Behaviour Research and Therapy, 44, 415-437.

https://doi.org/10.1016/j.brat.2005.02.007

${ }^{*}$ Ghielen, I., van Wegen, E. E. H., Rutten, S., de Goede, C. J. T., Houniet-de Gier, M., Collette, E. H., . . van den Heuvel, O. A. (2017). Body awareness training in the treatment of wearing-off related anxiety in patients with Parkinson's disease: Results from a pilot randomized controlled trial. Journal of Psychosomatic Research, 103, 1-8. https://doi.org/10.1016/j.jpsychores.2017.09.008

*Gifford, E. V., Kohlenberg, B. S., Hayes, S. C., Antonuccio, D. O., Piasecki, M. M., Rasmussen-Hall, M. L., \& Palm, K. M. (2004). Acceptance-based treatment for smoking cessation. Behavior Therapy, 35(4), 689-705. https://doi.org/10.1016/S0005-7894(04)80015-7

*Gifford, E. V., Kohlenberg, B. S., Hayes, S. C., Pierson, H. M., Piasecki, M. P., Antonuccio, D. O., \& Palm, K. M. (2011). Does acceptance and relationship focused behavior therapy contribute to bupropion outcomes? A randomized controlled trial of functional analytic psychotherapy and ACT for smoking cessation. Behavior Therapy, 42, 700-715. https://doi.org/10.1016/j.beth.2011.03.002

*Glassman, L. H. (2014). The effects of a brief acceptance-based behavior therapy vs. traditional cognitive behavior therapy for public speaking anxiety: Differential effects on performance and verbal working memory (Unpublished doctoral thesis). Drexel University, Philadelphia, PA, USA.

Gloster, A. T., Klotsche, J., Ciarrochi, J., Eifert, G., Sonntag, R., Wittchen, H. U., \& Hoyer, J. (2017). Increasing valued behaviors precedes reduction in suffering: Findings from a randomized 
controlled trial using ACT. Behaviour Research and Therapy, 91, 64-71.

https://doi.org/10.1016/j.brat.2017.01.013

Gloster, A. T., Klotsche, J., Gerlach, A. L., Hamm, A., Ströhle, A., Gauggle, S., . . Wittchen, H.-U. (2014). Timing matters: Mediators of outcomes in cognitive behavioral therapy for panic disorder with agoraphobia depend on the stage of treatment. Fournal of Consulting and Clinical Psychology, 82, 141-153. https://doi.org/10.1037/a0034555

Gloster, A. T., Sonntag, R., Hoyer, J., Meyer, A. H., Heinze, S., Ströhle, A., . . Wittchen, H.-U. (2015). Treating treatment-resistant patients with panic disorder and agoraphobia using psychotherapy: A randomized controlled switching trial. Psychotherapy \& Psychosomatics, 84, 100-109. https://doi.org/10.1159/000370162

*González-Fernández, S., Fernández-Rodríguez, C., Paz-Caballero, M. D., \& Pérez-Álvarez, M. (2018). Treating anxiety and depression of cancer survivors: Behavioral activation versus acceptance and commitment therapy. Psicothema, 30(1), 14-20. https://doi.org/10.7334/psicothema2017.396

${ }^{*}$ Gregg, J. A., Callaghan, G. M., Hayes, S. C., \& Glenn-Lawson, J. L. (2007). Improving diabetes selfmanagement through acceptance, mindfulness, and values: A randomized controlled trial. Journal of Consulting and Clinical Psychology, 75(2), 336-343. https://doi.org/10.1037/0022-006X.75.2.336

*Hancock, K. M., Swain, J., Hainsworth, C. J., Dixon, A. L., Koo, S., Munro, K., . . Munro, K. (2018). Acceptance and commitment therapy versus cognitive behavior therapy for children with anxiety: Outcomes of a randomized controlled trial. Journal of Clinical Child \& Adolescent Psychology, 47(2), 296-311. https://doi.org/10.1080/15374416.2015.1110822

Hatchett, G. T., \& Park, H. L. (2003). Comparison of four operational definitions of premature termination. Psychotherapy: Theory, Research, Practice, Training, 40(3), 226-231. https://doi.org/10.1037/0033-3204.40.3.226

*Hayes, L., Boyd, C. P., \& Sewell, J. (2011). Acceptance and commitment therapy for the treatment of adolescent depression: A pilot study in a psychiatric outpatient setting. Mindfulness, 2(2), 86-94. https://doi.org/10.1007/s12671-011-0046-5

Hayes, S. C., Hayes, S. C., Strosahl, K. D., \& Wilson, K. G. (2012). Acceptance and commitment therapy. New York, NY, USA: Guilford Press.

Hayes, S. C., Luoma, J. B., Bond, F. W., Masuda, A., \& Lillis, J. (2006). ACT: Model, processes and outcomes. Behaviour Research and Therapy, 44, 1-25. https://doi.org/10.1016/j.brat.2005.06.006

${ }^{*}$ Hayes, S. C., Wilson, K. G., Gifford, E. V., Bissett, R., Piasecki, M., . . Gregg, J. (2004). A preliminary trial of twelve-step facilitation and acceptance and commitment therapy with polysubstance-abusing methadone-maintained opiate addicts. Behavior Therapy, 35(4), 667-688. https://doi.org/10.1016/S0005-7894(04)80014-5

*Hayes-Skelton, S. A., Roemer, L., \& Orsillo, S. M. (2013). A randomized clinical trial comparing an acceptance-based behavior therapy to applied relaxation for generalized anxiety disorder. Journal of Consulting and Clinical Psychology, 81(5), 761-773. https://doi.org/10.1037/a0032871 
*Hernández-López, M., Luciano, M. C., Bricker, J. B., Roales-Nieto, J. G., \& Montesinos, F. (2009). Acceptance and commitment therapy for smoking cessation: A preliminary study of its effectiveness in comparison with cognitive behavioral therapy. Psychology of Addictive Behaviors, 23(4), 723-730. https://doi.org/10.1037/a0017632

*Hesser, H., Gustafsson, T., Lundén, C., Henrikson, O., Fattahi, K., Johnsson, E., . . Andersson, G. (2012). A randomized controlled trial of internet-delivered cognitive behavior therapy and acceptance and commitment therapy in the treatment of tinnitus. Fournal of Consulting and Clinical Psychology, 80(4), 649-661. https://doi.org/10.1037/a0027021

Hunsley, J., Aubry, T. D., Verstervelt, C. M., \& Vito, D. (1999). Comparing therapist and client perspectives on reasons for psychotherapy termination. Psychotherapy, 36, 380-388. https://doi.org/10.1037/h0087802

*Juarascio, A., Shaw, J., Forman, E., Timko, C. A., Herbert, J., Butryn, M., . . Lowe, M. (2013). Acceptance and commitment therapy as a novel treatment for eating disorders: An initial test of efficacy and mediation. Behavior Modification, 37(4), 459-489. https://doi.org/10.1177/0145445513478633

Kacker, R. N. (2004). Combining information from interlaboratory evaluations using a random effects model. Metrologia, 41(3), 132-136. https://doi.org/10.1088/0026-1394/41/3/004

Karekla, M. (2004). A comparison between acceptance-enhanced panic control treatment and panic control treatment for panic disorder (Unpublished doctoral dissertation). University of New York, New York City, NY, USA.

*Kemani, M. K., Hesser, H., Olsson, G. L., Lekander, M., \& Wicksell, R. K. (2016). Processes of change in acceptance and commitment therapy and applied relaxation for long-standing pain. European fournal of Pain, 20(4), 521-531. https://doi.org/10.1002/ejp.754

*Kingston, J. (2008). A pilot randomized control trial of ACT vs. CBT-treatment as usual (CBT-TAU) for a heterogeneous group of treatment resistant patients (Unpublished doctoral thesis). University of Southampton, Southampton, United Kingdom.

${ }^{*}$ Kocovski, N. L., Fleming, J. E., Hawley, L. L., Huta, V., \& Antony, M. M. (2013). Mindfulness and acceptance-based group therapy versus traditional cognitive behavioral group therapy for social anxiety disorder: A randomized controlled trial. Behaviour Research and Therapy, 51(12), 889-898. https://doi.org/10.1016/j.brat.2013.10.007

*Lang, A. J., Schnurr, P. P., Jain, S., He, F., Walser, R. D., Bolton, E., .. Strauss, J. (2017). Randomized controlled trial of acceptance and commitment therapy for distress and impairment in OEF/OIF/OND veterans. Psychological Trauma, 9(S1), 74-84. https://doi.org/10.1037/tra0000127

*Lanza, P. V., Garcia, P. F., Lamelas, F. R., \& González-Menéndez, A. (2014). ACT vs. CBT in the treatment of substance use disorder with incarcerated women. fournal of Clinical Psychology, 70(7), 644-657. https://doi.org/10.1002/jclp.22060

*Lassen, E. W. (2010). The effects of acceptance and commitment therapy (ACT) on anxiety in people with psychosis (Unpublished doctoral dissertation). California Institute of Integral Studies, San Francisco, CA, USA. 
*Lillis, J., Niemeier, H. M., Thomas, J. G., Unick, J., Ross, K. M., Leahey, T. M., . . Wing, R. R. (2016). A randomized trial of an acceptance-based behavioral intervention for weight loss in people with high internal disinhibition. Obesity, 24(12), 2509-2514. https://doi.org/10.1002/oby.21680

Linehan, M. M. (1993). Cognitive behavioral treatment of borderline personality disorder. New York, NY, USA: The Guilford Press.

*Luciano, J. V., Guallar, J. A., Aguado, J., López-Del-Hoyo, Y., Olivan, B., Magallón, R., . . GarciaCampayo, J. (2014). Effectiveness of group acceptance and commitment therapy for fibromyalgia: A 6-month randomized controlled trial (EFFIGACT study). Pain, 155(4), 693-702. https://doi.org/10.1016/j.pain.2013.12.029

${ }^{*}$ Luoma, J. B., Kohlenberg, B. S., Hayes, S. C., \& Fletcher, L. (2012). Slow and steady wins the race: A randomized clinical trial of acceptance and commitment therapy targeting shame in substance use disorders. fournal of Consulting and Clinical Psychology, 80(1), 43-53. https://doi.org/10.1037/a0026070

${ }^{*}$ McCracken, L. M., Sato, A., Wainwright, D., House, W., \& Taylor, G. J. (2014). A feasibility study of brief group-based acceptance and commitment therapy for chronic pain in general practice: Recruitment, attendance, and patient views. Primary Health Care Research \& Development, 15(3), 312-323. https://doi.org/10.1017/S1463423613000273

${ }^{*}$ McMillan, T., Robertson, I. H., Brock, D., \& Chorlton, L. (2002). Brief mindfulness training for attentional problems after traumatic brain injury: A randomised control treatment trial. Neuropsychological Rehabilitation, 12(2), 117-125. https://doi.org/10.1080/09602010143000202

*Moffitt, R., \& Mohr, P. (2015). The efficacy of a self-managed acceptance and commitment therapy intervention DVD for physical activity initiation. British fournal of Health Psychology, 20(1), 115-129. https://doi.org/10.1111/bjhp.12098

${ }^{*}$ Moitra, E., LaPlante, A., Armstrong, M. L., Chan, P. A., \& Stein, M. D. (2017). Pilot randomized controlled trial of acceptance-based behavior therapy to promote HIV acceptance, HIV disclosure, and retention in medical care. AIDS and Behavior, 21(9), 2641-2649. https://doi.org/10.1007/s10461-017-1780-z

*Morton, J., Snowdon, S., Gopold, M., \& Guymer, E. (2012). Acceptance and commitment therapy group treatment for symptoms of borderline personality disorder: A public sector pilot study. Cognitive and Behavioral Practice, 19(4), 527-544. https://doi.org/10.1016/j.cbpra.2012.03.005

${ }^{*}$ Mosher, C. E., Secinti, E., Li, R., Hirsh, A. T., Bricker, J., Miller, K. D., . . Champion, V. L. (2018). Acceptance and commitment therapy for symptom interference in metastatic breast cancer patients: A pilot randomized trial. Supportive Care in Cancer, 26(6), 1993-2004. https://doi.org/10.1007/s00520-018-4045-0

*Mo'tamedi, H., Rezaiemaram, P., \& Tavallaie, A. (2012). The effectiveness of a group-based acceptance and commitment additive therapy on rehabilitation of female outpatients with chronic headache: Preliminary findings reducing 3 dimensions of headache impact. Headache: The Journal of Head and Face Pain, 52(7), 1106-1119.

https://doi.org/10.1111/j.1526-4610.2012.02192.x 
${ }^{*}$ Nordin, L., \& Rorsman, I. (2012). Cognitive behavioural therapy in multiple sclerosis: A randomized controlled pilot study of acceptance and commitment therapy. Fournal of Rehabilitation Medicine, 44(1), 87-90. https://doi.org/10.2340/16501977-0898

Olfson, M., Mojtabai, R., Sampson, N. A., Hwang, I., \& Kessler, R. C. (2009). Dropout from outpatient mental health care in the US. Psychiatric Services, 60(7), 898-907. https://doi.org/10.1176/ps.2009.60.7.898

Ong, C. W., Lee, E. B., \& Twohig, M. P. (2018). A meta-analysis of dropout rates in acceptance and commitment therapy. Behaviour Research and Therapy, 104, 14-33. https://doi.org/10.1016/j.brat.2018.02.004

${ }^{*}$ Palmeira, L., Pinto-Gouveia, J., \& Cunha, M. (2017). Exploring the efficacy of an acceptance, mindfulness \& compassionate-based group intervention for women struggling with their weight (Kg-Free): A randomized controlled trial. Appetite, 112, 107-116. https://doi.org/10.1016/j.appet.2017.01.027

*Parling, T., Cernvall, M., Ramklint, M., Holmgren, S., \& Ghaderi, A. (2016). A randomised trial of acceptance and commitment therapy for anorexia nervosa after daycare treatment, including five-year follow-up. BMC Psychiatry, 16(1), Article 272. https://doi.org/10.1186/s12888-016-0975-6

Pekarik, G. (1992). Relationship of clients' reasons for dropping out of treatment to outcome and satisfaction. Journal of Clinical Psychology, 48, 91-98. https://doi.org/10.1002/1097-4679(199201)48:1<91::AID-JCLP2270480113>3.0.CO;2-W

*Petersen, C. L., \& Zettle, R. D. (2009). Treating inpatients with comorbid depression and alcohol use disorders: A comparison of acceptance and commitment therapy versus treatment as usual. The Psychological Record, 59(4), 521-536. https://doi.org/10.1007/BF03395679

Petrisor, B. A., \& Bhandari, M. (2007). The hierarchy of evidence: Levels and grades of recommendation. Indian fournal of Orthopaedics, 41(1), 11-15. https://doi.org/10.4103/0019-5413.30519

Powers, M. B., Vörding, M. B. Z. V. S., \& Emmelkamp, P. M. (2009). Acceptance and commitment therapy: A meta-analytic review. Psychotherapy and Psychosomatics, 78(2), 73-80. https://doi.org/10.1159/000190790

Roe, D., Dekel, R., Harel, G., \& Fennig, S. (2006). Clients' reasons for terminating psychotherapy: A quantitative and qualitative inquiry. Psychology and Psychotherapy, 79, 529-538. https://doi.org/10.1348/147608305X90412

Ruiz, F. J. (2012). Acceptance and commitment therapy versus traditional cognitive behavioral therapy: A systematic review and meta-analysis of current empirical evidence. International fournal of Psychology \& Therapy, 12, 333-357.

${ }^{*}$ Scott, W., Chilcot, J., Guildford, B., Daly-Eichenhardt, A., \& McCracken, L. M. (2018). Feasibility randomized-controlled trial of online acceptance and commitment therapy for patients with complex chronic pain in the United Kingdom. European fournal of Pain, 22, 1473-1484.

https://doi.org/10.1002/ejp.1236 
*Shawyer, F., Farhall, J., Mackinnon, A., Trauer, T., Sims, E., Ratcliff, K., . . Copolov, D. (2012). A randomised controlled trial of acceptance-based cognitive behavioural therapy for command hallucinations in psychotic disorders. Behaviour Research and Therapy, 50(2), 110-121. https://doi.org/10.1016/j.brat.2011.11.007

*Shawyer, F., Farhall, J., Thomas, N., Hayes, S. C., Gallop, R., Copolov, D., \& Castle, D. J. (2017). Acceptance and commitment therapy for psychosis: Randomised controlled trial. British fournal of Psychiatry, 210(2), 140-148. https://doi.org/10.1192/bjp.bp.116.182865

*Shayeghian, Z., Hassanabadi, H., Aguilar-Vafaie, M. E., Amiri, P., \& Besharat, M. A. (2016). A randomized controlled trial of acceptance and commitment therapy for type 2 diabetes management: The moderating role of coping styles. PLOS ONE, 11(12), Article e0166599. https://doi.org/10.1371/journal.pone.0166599

*Simister, H. D., Tkachuk, G. A., Shay, B. L., Vincent, N., Pear, J. J., \& Skrabek, R. Q. (2018). Randomized controlled trial of online acceptance and commitment therapy for fibromyalgia. fournal of Pain, 19(7), 741-753. https://doi.org/10.1016/j.jpain.2018.02.004

${ }^{*}$ Smout, M. F., Longo, M., Harrison, S., Minniti, R., Wickes, W., \& White, J. M. (2010). Psychosocial treatment for methamphetamine use disorders: A preliminary randomized controlled trial of cognitive behavior therapy and acceptance and commitment therapy. Substance Abuse, 31(2), 98-107. https://doi.org/10.1080/08897071003641578

*Steiner, J. L., Bogusch, L., \& Bigatti, S. M. (2013). Values-based action in fibromyalgia: Results from a randomized pilot of acceptance and commitment therapy. Health Psychology Research, 1(3), Article e34. https://doi.org/10.4081/hpr.2013.1542

Stone, W. N., \& Rutan, J. S. (1984). Duration of treatment in group psychotherapy. International Journal of Group Psychotherapy, 34, 93-109. https://doi.org/10.1080/00207284.1984.11491364

*Stotts, A. L., Green, C., Masuda, A., Grabowski, J., Wilson, K., Northrup, T. F., . . Schmitz, J. M. (2012). A stage I pilot study of acceptance and commitment therapy for methadone detoxification. Drug \& Alcohol Dependence, 125(3), 215-222. https://doi.org/10.1016/j.drugalcdep.2012.02.015

Swift, J. K., Callahan, J. L., \& Levine, J. C. (2009). Using clinically significant change to identify premature termination. Psychotherapy, 46, 328-335. https://doi.org/10.1037/a0017003

Swift, J. K., \& Greenberg, R. P. (2012). Premature discontinuation in adult psychotherapy: A metaanalysis. Journal of Consulting and Clinical Psychology, 80, 547-559.

https://doi.org/10.1037/a0028226

*Thorsell, J., Finnes, A., Dahl, J., Lundgren, T., Gybrant, M., Gordh, T., \& Buhrman, M. (2011). A comparative study of 2 manual-based self-help interventions, acceptance and commitment therapy and applied relaxation, for persons with chronic pain. The Clinical fournal of Pain, 27(8), 716-723. https://doi.org/10.1097/AJP.0b013e318219a933

Todd, D. M., Deane, F. P., \& Bragdon, R.A. (2003). Client and therapist reasons for termination: A conceptualization and preliminary validation. Journal of Clinical Psychology, 59, 133-147. https://doi.org/10.1002/jclp.10123 
*Trompetter, H. R., Bohlmeijer, E. T., Veehof, M. M., \& Schreurs, K. M. (2015). Internet-based guided self-help intervention for chronic pain based on acceptance and commitment therapy: A randomized controlled trial. Journal of Behavioral Medicine, 38(1), 66-80.

https://doi.org/10.1007/s10865-014-9579-0

*Twohig, M. P., Hayes, S. C., Plumb, J. C., Pruitt, L. D., Collins, A. B., Hazlett-Stevens, H., \& Woidneck, M. R. (2010). A randomized clinical trial of acceptance and commitment therapy versus progressive relaxation training for obsessive-compulsive disorder. fournal of Consulting and Clinical Psychology, 78(5), 705-716. https://doi.org/10.1037/a0020508

${ }^{*}$ Tyrberg, M. J., Carlbring, P., \& Lundgren, T. (2017). Brief acceptance and commitment therapy for psychotic inpatients: A randomized controlled feasibility trial in Sweden. Nordic Psychology, 69(2), 110-125. https://doi.org/10.1080/19012276.2016.1198271

*Vakili, Y., Gharraee, B., Habibi, M., Lavasani, F., \& Rasoolian, M. (2013). The comparison of acceptance and commitment therapy with selective serotonin reuptake inhibitors in the treatment of obsessive-compulsive disorder. Zahedan fournal of Research in Medical Sciences, 16(10), 10-14.

*Wang, S., Zhou, Y., Yu, S., Ran, L., Liu, X., \& Chen, Y. (2017). Acceptance and commitment therapy and cognitive - Behavioral therapy as treatments for academic procrastination: A randomized controlled group session. Research on Social Work Practice, 27(1), 48-58. https://doi.org/10.1177/1049731515577890

*Weineland, S., Arvidsson, D., Kakoulidis, T. P., \& Dahl, J. (2012). Acceptance and commitment therapy for bariatric surgery patients, a pilot RCT. Obesity Research \& Clinical Practice, 6(1), e21-e30. https://doi.org/10.1016/j.orcp.2011.04.004

${ }^{*}$ Westin, V. Z., Schulin, M., Hesser, H., Karlsson, M., Noe, R. Z., Olofsson, U., . . Andersson, G. (2011). Acceptance and commitment therapy versus tinnitus retraining therapy in the treatment of tinnitus: A randomised controlled trial. Behaviour Research and Therapy, 49(11), 737-747. https://doi.org/10.1016/j.brat.2011.08.001

*Wetherell, J. L., Afari, N., Rutledge, T., Sorrell, J. T., Stoddard, J. A., Petkus, A. J., . . Atkinson, J. H. (2011b). A randomized, controlled trial of acceptance and commitment therapy and cognitivebehavioral therapy for chronic pain. Pain, 152(9), 2098-2107.

https://doi.org/10.1016/j.pain.2011.05.016

*Wetherell, J. L., Liu, L., Patterson, T. L., Afari, N., Ayers, C. R., Thorp, S. R., . . Petkus, A. J. (2011a). Acceptance and commitment therapy for generalized anxiety disorder in older adults: A preliminary report. Behavior Therapy, 42(1), 127-134. https://doi.org/10.1016/j.beth.2010.07.002

*White, R., Gumley, A., McTaggart, J., Rattrie, L., McConville, D., Cleare, S., \& Mitchell, G. (2011). A feasibility study of acceptance and commitment therapy for emotional dysfunction following psychosis. Behaviour Research and Therapy, 49(12), 901-907.

https://doi.org/10.1016/j.brat.2011.09.003

*Wicksell, R. K., Melin, L., Lekander, M., \& Olsson, G. L. (2009). Evaluating the effectiveness of exposure and acceptance strategies to improve functioning and quality of life in longstanding pediatric pain. Pain, 141, 248-257. https://doi.org/10.1016/j.pain.2008.11.006 
Wierzbicki, M., \& Pekarik, G. (1993). A meta-analysis of psychotherapy dropout. Professional Psychology: Research and Practice, 24, 190-195. https://doi.org/10.1037/0735-7028.24.2.190

*Wolitzky-Taylor, K. B., Arch, J. J., Rosenfield, D., \& Craske, M. G. (2012). Moderators and nonspecific predictors of treatment outcome for anxiety disorders: A comparison of cognitive behavioral therapy to acceptance and commitment therapy. Journal of Consulting and Clinical Psychology, 80(5), 786-799. https://doi.org/10.1037/a0029418

*Zettle, R. D. (2003). Acceptance and commitment therapy (ACT) vs. systematic desensitization in treatment of mathematics anxiety. The Psychological Record, 53(2), 197-215.

https://doi.org/10.1007/BF03395440

\section{EACLIPT}

Clinical Psychology in Europe (CPE) is the official journal of the European Association of Clinical Psychology and Psychological Treatment (EACLIPT).

\section{(4) leibniz-psychology.org}

PsychOpen GOLD is a publishing service by Leibniz Institute for Psychology Information (ZPID), Germany. 